\title{
DEM analysis of pile installation effect: comparing a bored and a driven pile
}

\section{Nuo Duan}

Lecturer, Institute of Foundation and Structure Technologies, Zhejiang Sci-Tech University, Hangzhou, P. R. China; MOE Key Laboratory of Soft Soils and Geoenvironmental Engineering, Zhejiang University, Hangzhou, 310027, P. R. China; formerly Department of Civil, Environmental \& Geomatic Engineering, University College London, London, UK (Orcid:0000-0003-2585-9594)

\section{Yi Pik Cheng}

Senior Lecturer, Department of Civil, Environmental \& Geomatic Engineering, University College London, London, UK

\section{Jun Wei Liu}

Associate Professor, Qingdao Technological University, Qindao, China; formerly Visiting research associate, Department of Civil, Evironmental \& Geomatic Engineering, University College London, U.K.

\begin{abstract}
This paper presents a two-dimensional Particle Flow Code (PFC2D) model of the Discrete Element Method (DEM) that is used to study the effects of pile installation in deep foundation. It is accepted widely that installation method affects pile behaviour, but there are still limited studies that compare and analyse the impacts systematically. In this paper, the DEM is used to explain the pile behaviour installed in granular soils. A rigid bored pile and a rigid driven pile of the same geometry were installed into an assembly of granular soil modelled under a high gravitation force. Behaviour of the driven pile during penetration compares well with published data, and the numerical data also provides further insights of the soil-pile interaction during the penetration process. After pile installation, comparisons of the subsequent pile-loading behaviour were made, showing different contributions of shaft and end bearing resistance between the bored pile and the driven pile. Furthermore, the impacts of having different pile weights and different soil friction angles were discussed. When considering the same pile and soil friction, the driven pile performed better in the pile load test because the soil was compressed during the driving process. In particular, it was found that the soil friction affects the bored pile and the driven pile in a different manner such that soil friction will take effect after certain depth for bored pile, however, it will have an impact at the beginning for driven pile. Micro-scale sliding fraction of the particles near the two piles was also used to
\end{abstract}


explain the observed phenomena.

KEYWORDS: bored and driven pile, discrete element method, numerical modelling, sands

\section{Notation}

\begin{tabular}{|c|c|}
\hline$d_{10}$ & $10 \%$ particle diameter $(\mathrm{mm})$ \\
\hline$d_{50}$ & $50 \%$ particle diameter $(\mathrm{mm})$ \\
\hline$d_{60}$ & $60 \%$ particle diameter $(\mathrm{mm})$ \\
\hline$d_{b p}$ & the distance between the centre of pile and model boundary $(\mathrm{mm})$ \\
\hline$d_{p p}$ & the distance between the centres of two adjacent particles $(\mathrm{mm})$ \\
\hline$d_{\text {pile }}$ & pile diameter $(\mathrm{mm})$ \\
\hline$D$ & model depth (mm) \\
\hline$E_{p}$ & Particle Young's modulus (Pa) \\
\hline$g$ & the gravity $\left(\mathrm{m} / \mathrm{s}^{2}\right)$ \\
\hline$h_{\text {model }}$ & the height of model (mm) \\
\hline$H$ & the vertical applied load $(\mathrm{N})$ \\
\hline$k$ & particle linear contact stiffness $(\mathrm{N} / \mathrm{m})$ \\
\hline$k_{n}$ & particle normal contact stiffness $(\mathrm{N} / \mathrm{m})$ \\
\hline$k_{s}$ & particle shear contact stiffness $(\mathrm{N} / \mathrm{m})$ \\
\hline$L$ & penetration depth (mm) \\
\hline$m_{r}$ & the radius of measurement circle (mm) \\
\hline$n_{p}$ & the ratio of pile diameter to $d_{50}$ \\
\hline$n_{m}$ & the ratio of model diameter to pile diameter \\
\hline$n_{h}$ & the ratio of model height to pile diameter \\
\hline$N_{s}$ & scaling ratio \\
\hline$\mu$ & friction coefficient of the particles \\
\hline$\gamma$ & bulk unit weight $\left(\mathrm{kN} / \mathrm{m}^{3}\right)$ \\
\hline$w_{\text {model }}$ & the width of the model container (mm) \\
\hline$u$ & the displacement of pile bottom (mm) \\
\hline$y$ & penetration depth (mm) \\
\hline$x$ & the coordination of $x$ plane $(\mathrm{mm})$ \\
\hline
\end{tabular}




\section{Introduction}

It is known that different installation methods can result in different interactions between the pile and surrounding soils, and this will affect the loading bearing capacity (shaft and tip resistance capacity) of the pile. This factor is quite vital and affects the design of the pile foundation. However, there are still uncertainties in the interaction of the pile and the soil. Conventional methods researching the impact of the installation method were based on the laboratory, field tests and numerical simulations. Albuquerque et al. (2011) compared the behaviour of 3 types of deep pile (bored, continuous flight auger (CFA) and precast driven piles) by the static pile load tests from experimental field to laboratory tests. The result showed that the shaft and tip resistance of the bored and CFA piles were similar although CFA pile contributed less disturbance to surrounding soil at the pile tip. Adejumo and Boiko (2013) studied field tests (sandy soil) by comparing the driven and bored piles under the axial load. Their tests showed that driven installation technique resulted in the more surrounding soil displacement compared to the bored installation technique, and it also resulted in a smaller bearing capacity of the pile (by approximately $12-18 \%$ ) in a fully mobilised soil resistance and loading case. Although there are many finite element method (FEM) simulations published to study the behaviour of pile and its interaction to the surrounding sandy soil, such as Wehnert and Vermeer (2004), Broere and Tol (2006), and De Gennaro, Frank, and Said (2008), it is accepted that FEM does not perform well in simulations involving discontinued phenomena such as fractures and shear planes. Ting, Corkum, Kauffman, and Greco (1989) pointed out that there were potential problems with the assumption of continua, and it was due to soil's inherent granular nature and the consequent deformation \& failure modes.

An alternative numerical method is the Discrete Element Method (DEM). It is referred to, by Cundall and Strack (1979), as the particular discrete element scheme that uses deformable (soft) contacts and an explicit time-domain solution of the original equations of motion. The PFC-2D is a programming code which is developed by ITASCA. This software uses the DEM to simulate the finite movements, rotations and interaction of discrete particles including complete detachment. It can model either bonded (cemented) or unbounded (granular) group of particles (Itasca, 2004), and also particles of any shape using the clump logic. Therefore, it is a powerful tool to simulate complex problems in solid mechanics, rock mechanics, and granular flow. The DEM is rapidly gaining acceptance in the geotechnical research community as a useful tool for investigating the behaviour of soils, and key aspects of soil material responses have been demonstrated to "emerge" from DEM models (O'Sullivan, 2011). While the major contribution of DEM in geomechanics to date has been to advance understanding of the fundamental nature of soil behaviour (e.g., Cheng, Nakata, and Bolton (2003), Y. H. Wang and Leung (2008)), it is also recognized that DEM-based models can be applied directly to solve larger-scale engineering problems (Bertrand, Nicot, Gotteland, \& 
Lambert, 2008; Cundall, 2001; Maynar \& Rodríguez, 2005).

Most pile-related studies that used the DEM concentrate on the cone penetration test (CPT), because CPT is a well-established in-site test to classify soil and to estimate the soil properties in geotechnical engineering (Been, Jefferies, Crooks, \& Rothenburg, 1987; Robertson, 1986; Schertmann, 1977; Sladen, 1989; H. S. Yu, 2006). Some of the DEM cone penetration models were performed using two-dimensional (2D) elements or disks (Calvetti \& Nova, 2005; Huang \& Ma, 1994; M. J. Jiang, Yu, \& Harris, 2010). Only recently when 3D simulations of the CPT problem have been performed (J Butlanska, Arroyo, \& Gens, 2010). Arroyo, Butlanska, Gens, Calvetti, and Jamiolkowski (2011) showed that a CPT performed in a virtual calibration chamber filled with a discrete analogue of Ticino sand resulted in steady-state penetration values that were in close quantitative agreement with predictions based on correlations previously established in physical chambers. Such correlations between tip resistance, initial mean stress, and density (Jamiolkowski, Lo Presti, \& Manassero, 2003) were still the cornerstone of much practical field work interpretation, and the agreement noted was therefore encouraging. Similar work, but with a somewhat different emphasis, was recently presented by Mcdowell, Falagush, and Yu (2012) and Lin and Wu (2012).

The first DEM numerical simulation to deep penetration in sand was applied by Huang and Ma (1994) and they found that the penetration mechanism and soil dilatancy in the granular soil were both affected by the loading history. Based on their study, M. J. Jiang et al. (2010) developed and improved the 2D DEM simulation to deep penetration, and described the penetration mechanism from the viewpoints of deformation patterns, displacement paths, velocity field, stress fields and stress paths. Vallejo and Lobo-Guerrero (2005) also compared behaviour of 3 driven piles of different shapes, including a closed tip, an open end and a cone tip respectively, in breakable granular soil. They found that the closed tip pile had the highest penetration resistance and resulted in the highest amount of crushing on particles surrounding it, but the cone tip pile performed worst in both the penetration resistance and the crushing of surrounding particles.

Regardless of the dimensional restriction, the 2D modelling saves computational cost compared to 3D modelling, hence allows modelling a larger number of soil particles for engineering problems. However, the comparison with tests on real soils remained qualitative rather than quantitative. In this paper, the numerical DEM method was used to reveal the detailed impacts of two typical pile installation methods by carefully inserting the same pile into the same homogenous soil, followed by subsequent axial loading. Limited micromechanical analyses, except the sliding fraction of the surrounding particles, was shown due to a space limitation. 


\section{Model description}

\subsection{General model setup}

All 2D-DEM analyses in this investigation were performed using an increased gravity field of $100 \mathrm{~g}$. The main reason of increasing the gravitation field was to increase the speed of the simulations in order to reach a convergent qusi-static solution in a shortened computational time. Also it was also found that, under the condition of 100g gravity, this series of FLAC-2D simulation data were found to match the same stress level observed in centrifuge test at 100g, will be seen in Figure 3. The detailed comparison of the numerical data and a set of centrifuge test data were shown by N. Duan (2016); N Duan and Cheng (2016); N. Duan, Cheng, and $\mathrm{Xu}$ (2017). The specific scaling up relationship and their potential problem will be discussed later in this section.

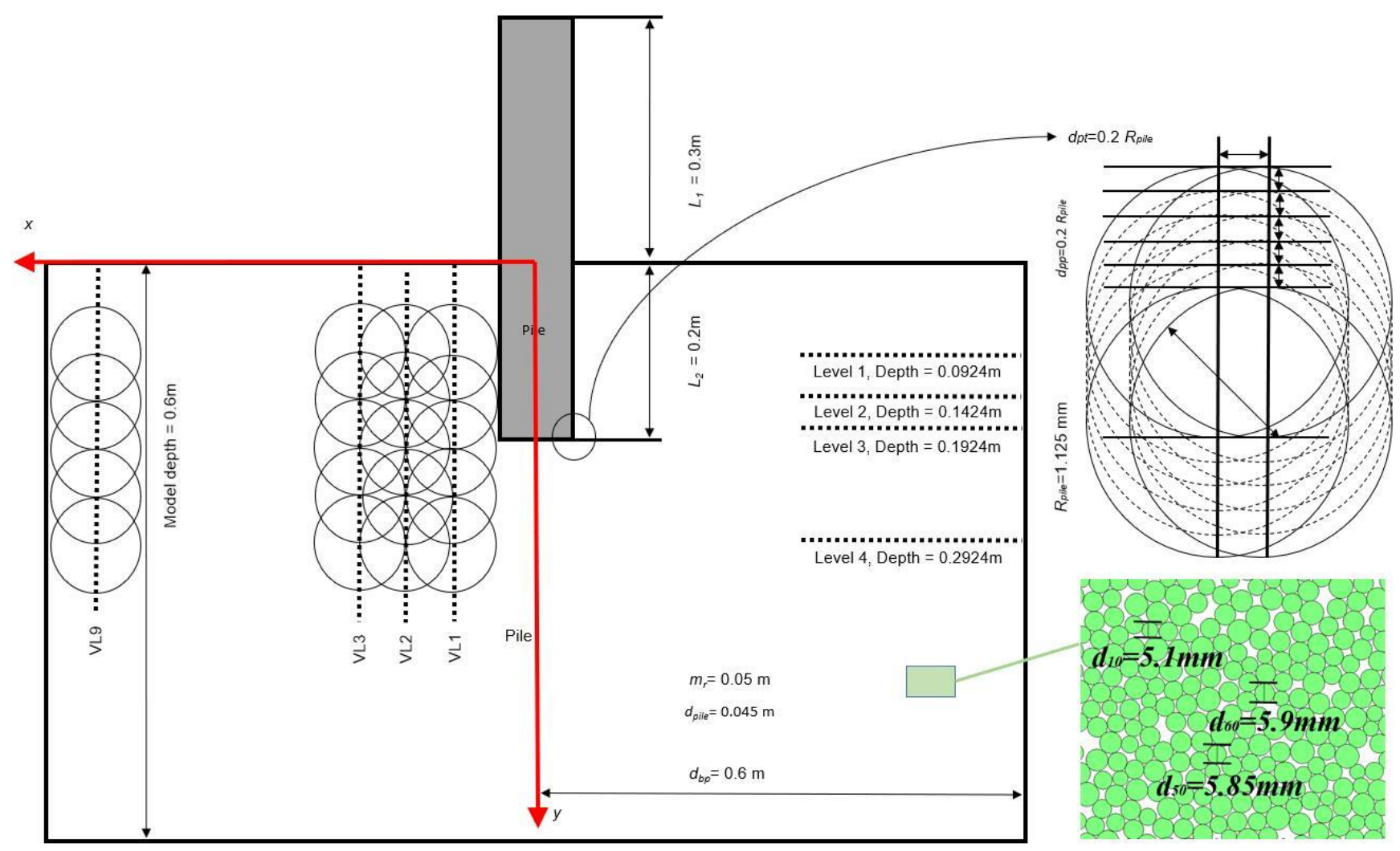

Figure 1. Schematic view of the PFC model in model scale (Subset shows a typical particle assembly at equilibrium before pile installation.)

A schematic view of the DEM model is shown in Figure 1, which includes a solid rigid pile with diameter $d_{p i l e}=45 \mathrm{~mm}$ and penetration depth (fully embedded depth), $L=200 \mathrm{~mm}\left(L=4.44 d_{\text {pile }}\right)$. This represents a prototype pile (100 times of length) with diameter of $4.5 \mathrm{~m}$ and penetration length $20 \mathrm{~m}$, which is the dimension of a typical large-diameter rigid monopile for wind turbine foundation. The model width of the 
container is $\mathrm{W}=1.2 \mathrm{~m}\left(d_{b p}=\mathrm{W} / 2=0.6 \mathrm{~m}\right.$, as is seen in Figure 1$)$, and the model depth is $\mathrm{D}=0.6 \mathrm{~m}$. This width is twice of the model in N Duan and Cheng (2016) in order to further eliminate the boundary effect, giving $d_{b p}=12.33 d_{p i l e}$, and $(D-L)=8.89 d_{\text {pile. }}$. A view of the particle assembly is also shown in the subset of Figure 1, and $d_{50}=5.85 \mathrm{~mm}$. This particle size might represent that of very large particles in the prototype scale. The particle size should have been ideally scaled but reduced particle sizes were not used due to the associated simulation costs. Instead, the ratio of pile diameter and the particle diameter was kept to be minimum of around $8, d_{\text {pile }}=7.69 d_{50}$, in this study.

Centrifuge testing allows small models to be used to accurately represent the behaviours of prototype (full-scale) geotechnical problems, following the scaling laws presented by Schofield (1980) (see Table 1). Following Feng, Han, Owen, and Loughran (2009) and Feng and Owen (2014), mechanical similarity of the scaled model requires the use of scale-invariant. For the linear contact force-displacement law $F=k u$ acting between each pair of contacting particles in PFC2D, the linear stiffness $k$ has a unit of N/m. So the particle stress-strain relation for the $2 \mathrm{D}$ problems becomes $\sigma=k \varepsilon$. This means that, if the coefficient $k$ is a constant, the linear contact law is scale-invariant for 2D problems. However, when applying the centrifuge scaling laws in Table 1 to 2D-DEM problems, the unit of stress was taken as $\mathrm{N} / \mathrm{m}^{2}$ by considering unit thickness. This might create a fundamental scaling problem making it different from centrifuge test. Despite the existing issue, DEM was still used to model the deep foundation or centrifuge test due to its ability to simulate large deformation (M. J. Jiang et al., 2010; Marshall, Elkayam, Klar, \& Mair, 2010).

Table 1. Centrifuge Scaling Laws (Schofield, 1980).

\begin{tabular}{|c|c|c|c|c|c|c|c|}
\hline Parameter & $\begin{array}{c}\text { Acceleration } \\
\left(\mathrm{m} / \mathrm{s}^{2}\right)\end{array}$ & $\begin{array}{c}\text { Force } \\
(\mathrm{N})\end{array}$ & $\begin{array}{c}\text { Stress } \sigma \\
\left(\mathrm{N} / \mathrm{m}^{2}\right)\end{array}$ & $\begin{array}{c}\text { Strain } \\
\varepsilon\end{array}$ & Rotation & $\begin{array}{c}\text { Displacem } \\
\text { ent }(\mathrm{m})\end{array}$ & Mass \\
\hline $\begin{array}{c}\text { Model/ } \\
\text { Prototype }\end{array}$ & $N_{s}$ & $1 / N_{s}^{2}$ & 1 & 1 & 1 & $1 / N$ & $1 / N_{s}^{3}$ \\
\hline
\end{tabular}

In a large scale model, we prefer to obtain a homogeneity in soil condition that have nice stress distributions with linearly increasing overburden stress without too much deviations. Hence, the stress state would be same as that to the real soil profile. Also porosity is the same in the same horizontal level, i.e. different vertical columns has the same porosity distribution (linearly changing with depth). In order to do this, a modified particle generation method, referred to as the Grid-Method (GM), was proposed to generate this type of homogeneous and realistic specimen for the DEM study (N Duan \& Cheng, 2016). 
In the first stage during sample generation, sand particles inside each grid were generated one by one, as illustrated in Duan \& Cheng, 2016. Approximately 280 particles were created in each grid, with an initial average porosity of 0.25 , and the model was brought to the equilibrium state. After the bottom layer of soil was formed, all the internal walls between the grids were deleted and the locations of the surface soil particles were temporarily fixed until the layer above was successfully formed. This process was repeated until all the particles in all 36 grids were created, resulting in a total of 10,080 particles in the whole model. In the second stage, a $100 \mathrm{~g}$ gravity force in the $y$ direction was applied to the whole system, and the PFC model was numerically cycled again to obtain the equilibrium state. At this point the porosity had reached the final average value of 0.185 . In the third stage, the sand particles inside the pile zone were deleted and a series of clumps were created to model the rigid monopile. The system was then cycled to an equilibrium state again with the pile in place.

According to the 2D PFC manual, the quantitative value of particle normal stiffness $k_{n}$ could be twice of its particle Young's Modulus $E_{p}$. The sand particles were made of disks with a maximum diameter of $7.05 \mathrm{~mm}$, a minimum diameter of $4.5 \mathrm{~mm}$, an average grain diameter $d_{50}=5.85 \mathrm{~mm}$ and uniformity coefficient $C_{u}=$ $d_{60} / d_{10}=1.26$ (see Figure 2). Table 2 shows the input parameters used in the DEM simulations. Due to the construction of pile, the density of pile was chose $500 \mathrm{~kg} / \mathrm{m}^{3}$ (see section 2.3 for detail).

Table 2. Input parameters for DEM simulations.

\begin{tabular}{|l|c|}
\hline Density of sand particles $\left(\mathrm{kg} / \mathrm{m}^{3}\right)$ & 2650 \\
\hline Density of particles for pile $\left(\mathrm{kg} / \mathrm{m}^{3}\right)$ & 500 \\
\hline Particle diameters, $d_{\text {particle }}(\mathrm{mm})$ & Figure 2 \\
\hline Average particle size, $d_{50}(\mathrm{~mm})$ & 5.85 \\
\hline Model pile diameters, $d_{\text {pile }}(\mathrm{mm})$ & 45 \\
\hline Model pile length, $l_{\text {pile }}(\mathrm{mm})$ & 200 \\
\hline Model container width, $w_{\text {model }}(\mathrm{mm})$ & 1200 \\
\hline Model container depth, $h_{\text {model }}(\mathrm{mm})$ & 600 \\
\hline Friction coefficient of the particles $\mu(-)$ & $0.2,0.5,0.8$ \\
\hline Friction coefficient of pile $\&$ walls $\mu(-)$ & 0.5 \\
\hline Particles Young's Modulus, $E_{p}(\mathrm{~Pa})$ & $4 \mathrm{e} 7$ \\
\hline $\begin{array}{l}\text { Contact normal stiffness of pile } \& \text { particles, } k_{n} \\
(\mathrm{~N} / \mathrm{m})\end{array}$ & $8 \mathrm{e} 7$ \\
\hline Particle stiffness ratio $\left(k_{s} / k_{n}\right)$ & 0.25 \\
\hline
\end{tabular}




\begin{tabular}{|l|c|}
\hline Contact normal stiffness of walls, $k_{n}(\mathrm{~N} / \mathrm{m})$ & $6 \mathrm{e} 12$ \\
\hline Initial average porosity & 0.25 \\
\hline Final average porosity (final equilibrium) & 0.185 \\
\hline Bulk unit weight $\gamma$ bulk $\left(\mathrm{kN} / \mathrm{m}^{3}\right)$ & 2115.3 \\
\hline
\end{tabular}

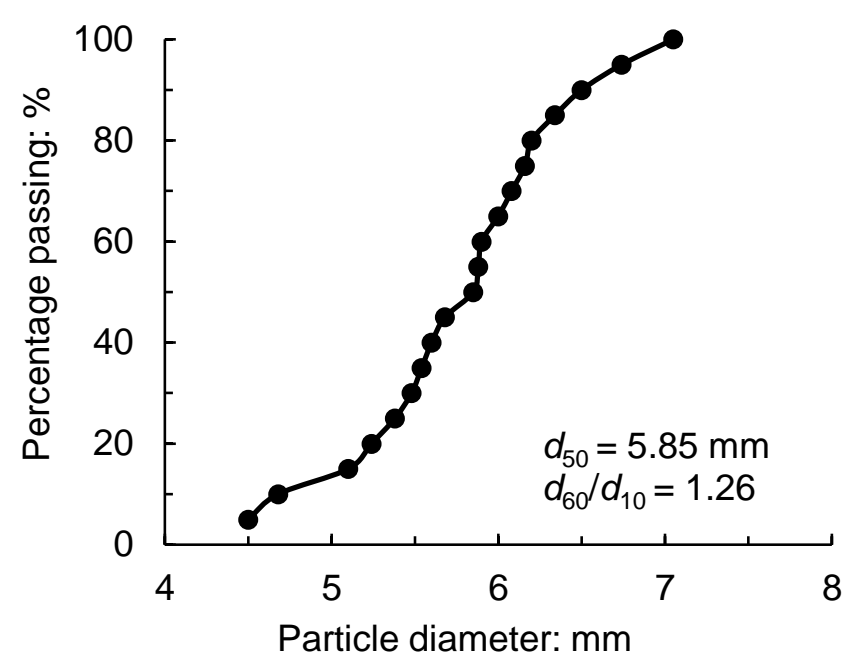

Figure 2. Distribution of model scale grain sizes in DEM analyses.

Based on a comparison of parameters used in other experiment and DEM simulations (see Table 3), it was found that the parameter $d_{\text {pile }} / d_{50}$ affected the accuracy of experiment and numerical modelling (M.D. Bolton \& Gui, 1993). In this model, for the aim of efficiency, the value of $d_{\text {pile }} / d_{50}$ was chosen as 7.69 which closed to Vallejo and Lobo-Guerrero (2005). A comparison of a range of model parameters with other published data is shown in Table 3.

Table 3. General test configurations for various laboratories

\begin{tabular}{|l|l|l|l|l|l|l|}
\hline $\begin{array}{l}\text { Diameter of } \\
\text { pile, } \\
(\mathrm{mm})\end{array}$ & $\begin{array}{l}\text { Average } \\
\text { grain } \\
\text { diameter, } \\
d_{50}(\mathrm{~mm})\end{array}$ & $\frac{d_{\text {pile }}}{d_{50}}$ & $\frac{w_{\text {model }}}{d_{\text {pile }}}$ & $\frac{h_{\text {model }}}{d_{\text {pile }}}$ & $\begin{array}{l}\text { Gravity } \\
\left(9.8 \mathrm{~m} / \mathrm{s}^{2}\right)\end{array}$ & Case \\
\hline 1 & 0.172 & 5.81 & 12 & 25 & 2000 & $\begin{array}{l}\text { Z. Zhang and Wang } \\
(2015) \text { [3D] }\end{array}$ \\
\hline
\end{tabular}




\begin{tabular}{|l|l|l|l|l|l|l|}
\hline 8 & 0.1735 & 46.1 & 30 & 30 & $50 / 100 / 150$ & $\begin{array}{l}\text { J. Wang and Zhao } \\
(2014) \text { [2D] }\end{array}$ \\
\hline 159.98 & 7.6 & 21.1 & 31.25 & 10.16 & 20 & $\begin{array}{l}\text { M. Jiang, Dai, Cui, } \\
\text { Shen, and Wang } \\
\text { (2014) [2D] }\end{array}$ \\
\hline 71.2 & 26.5 & 2.7 & 16.86 & 9.83 & 1 & $\begin{array}{l}\text { Arroyo et al. (2011) } \\
\text { [3D] }\end{array}$ \\
\hline 71.2 & 26.5 & 2.7 & 16.86 & 9.83 & 1 & $\begin{array}{l}\text { Joanna Butlanska, } \\
\text { Arroyo, and Gens } \\
\text { (2009) [3D] }\end{array}$ \\
\hline 36 & 2.925 & 12.3 & 8.75 & 8 & 1000 & $\begin{array}{l}\text { M. J. Jiang et al. } \\
\text { (2010) [2D] }\end{array}$ \\
\hline 30 & 3 & 10.0 & 13.33 & 26.66 & 1 & $\begin{array}{l}\text { Vallejo and } \\
\text { Lobo-Guerrero } \\
\text { (2005) [2D] }\end{array}$ \\
\hline 10 & 0.22 & 45.5 & $21 / 85$ & & $40 / 70 / 125$ & $\begin{array}{l}\text { M. D. Bolton et al. } \\
\text { (1999) [centrifuge } \\
\text { tests] }\end{array}$ \\
\hline 45 & 5.85 & 7.69 & 26.67 & 13.33 & 100 & \\
\hline
\end{tabular}

\subsection{Initial stress state}

Figure 3 (a) presents the distribution of void ratio in DEM model after final equilibrium. The green line is average void ratio and the red lines are the range of void ratio at different locations. The GM method has produced a uniform distribution of void ratio, decreasing linearly with depth. Figure 3(b) shows the distributions of average lateral and vertical stress distributions that also vary linearly with depths, and the coefficient of earth pressure $K_{o}=0.65$. The vertical stresses $\sigma_{v}$ match well with theoretical values calculated using the bulk density obtained at the equilibrium state using $\sigma_{v}=\rho g h$, where $\rho$ is sample density, $g$ is the applied gravity, and $h$ is prototype depth from ground surface (N Duan \& Cheng, 2016). 


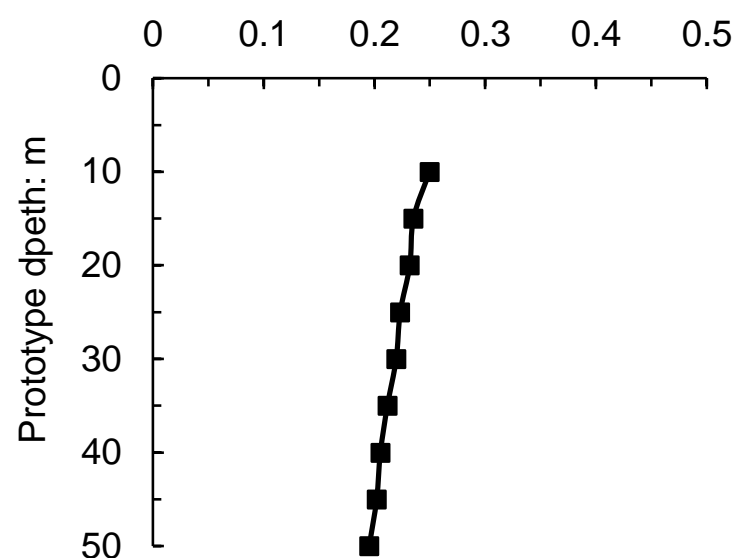

(a)

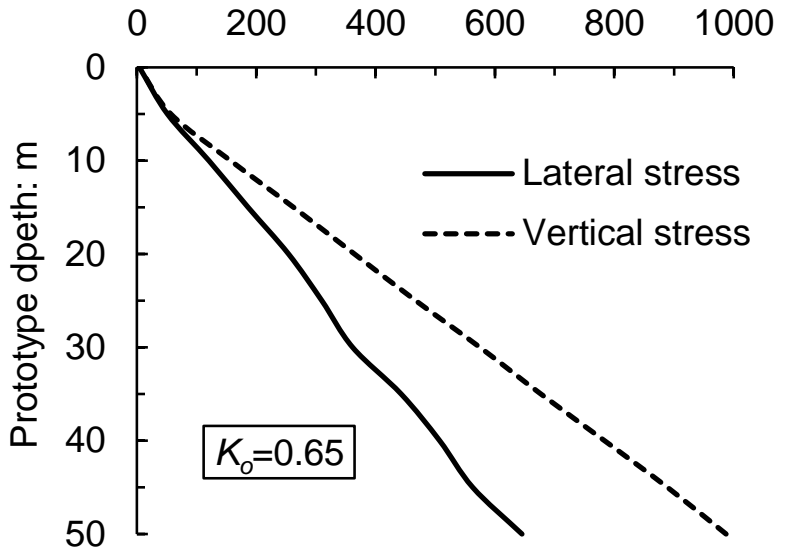

(b)

Figure 3. (a) Initial distribution of void ratio in DEM analyses; (b) Average lateral and vertical stress.

\subsection{A rough rigid pile model}

The pile was made of particles with radius $1.125 \mathrm{~mm}$ (see Figure 1). These particles overlapped each other forming a rough rigid pile, and the distance between the centres of two adjacent particles is $d_{p p}$. The input density of these pile particles was scaled such that the overall pile has the weight of a steel pile. Due to the small size particles and the short distance between every two balls, the surface of pile is smooth enough to eliminate the occurrence of any out of direction shaft resistance. In the calculation of shaft resistance, the embedded pile length was divide in to 10 parts with $20 \mathrm{~mm}$ each.

\subsection{DEM simulations programme}

Table 4 summarises the all DEM simulation tests, "BE" means bored pile with the flat-end, and "DE" means driven pile with flat-end. There were 6 tests in total to compare the effects of different soil characteristics. Numbers " $1,2,3$ " mean the different friction $0.2,0.5,0.8$ " of the surrounding soils respectively. For all simulations, the friction coefficient of pile is always 0.5 .

Table 4. General test configurations for DEM models.

\begin{tabular}{|c|c|c|c|c|c|c|}
\hline Simulation name & BE1 & BE2 & BE3 & DE1 & DE2 & DE3 \\
\hline Particles friction coefficient & 0.2 & 0.5 & 0.8 & 0.2 & 0.5 & 0.8 \\
\hline
\end{tabular}

The embedment depth of the two pile types (driven pile and bored pile) are both $0.2 \mathrm{~m}$, but their installation methods are entirely different. For driven pile, it was pushed into the soil by a stepwise increase of vertical 
load until the desired depth was reached, therefore the scaling of time was not considered in this paper. Under each specific load increment, the system was cycled to equilibrium until the pile displacement reached its maximum, and then the following load was applied.

The PFC inherent "measurement circle" function is introduced here to measure the information of soil elements at different locations surrounding the pile. The size and locations of these measurement circles were described in Figure 1; $m_{r}$ is the radius of measurement circle and the value is $0.05 \mathrm{~m}$. Note only one side of model was analysed due to the symmetrical nature of the problem. Four levels of depths (with the deepest Level $10.1 \mathrm{~m}$ below pile tip, and the shallowest Level 4 at mid-depth of the pile, i.e. $0.1 \mathrm{~m}$ above pile tip) were monitored, together with nine horizontal locations (VL1,VL2...VL9).

\section{Piles installation}

\subsection{Driven pile}

All dimensions and measurements in the following sections are shown in model scale. The driven pile was pushed by a stepwise increase of vertical load level, such as $0 \mathrm{kN}, 10 \mathrm{kN}, 20 \mathrm{kN}, 40 \mathrm{kN}$ and so on, until around $150 \mathrm{kN}$. At each load level, the pile top will be applied with the corresponding vertical load, at that moment, the vertical load remained constant, the whole DEM system was cycled until the equilibrium state. This state was judged by the ratio of average unbalanced force to average contact force in the system. At the end of the installation, the pile was penetrated to the maximum depth. Figure 4 (a) plots the model vertical load against the normalised pile penetration when installing at different soil conditions, in which the vertical load is calculated by the summation of applied vertical load and the self-weight of pile. Although the slopes of the various load-displacement curves are very similar regardless of soil friction after the pile penetrated the soil, the soil with the highest friction coefficient (DE3, $\mu=0.8$ ) provides the highest initial penetration resistance, hence requiring the highest vertical force to reach a certain penetration depth. Figure 4 (b) shows the total, shaft and base resistance developed during installation in the case when the soil friction is 0.5 (DE2). It is clear that total resistance increases approximately linearly with penetration depth, in which the base resistance contributes to the majority of the total resistance. It is therefore evident that the penetration

resistance of piles depends mostly on the base resistance, as reported by F. Yu (2004) and Liu, Zhang, Yu, and Xie (2012). 


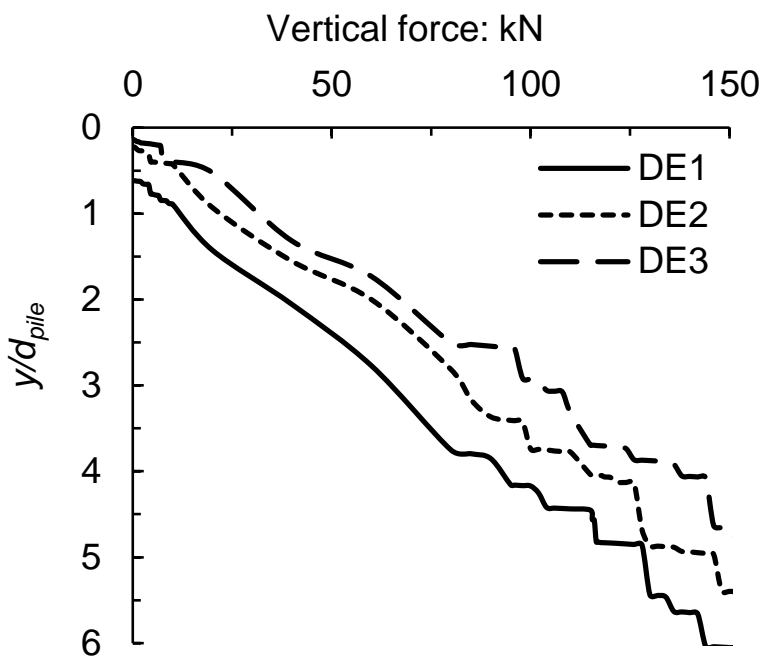

(a)

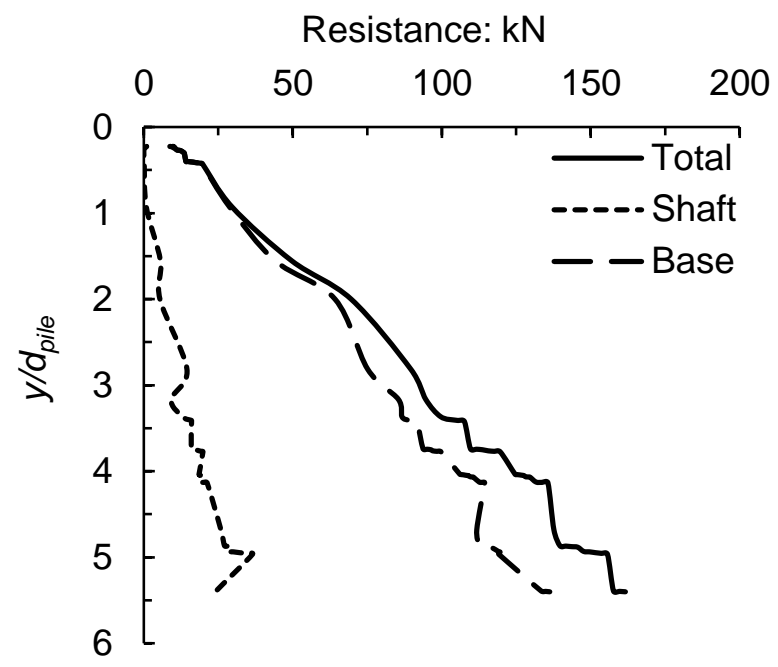

(b)

Figure 4. (a) Load-settlement curves installing at different soil conditions ( $\mu=0.2,0.5 \& 0.8)$. (b) Vertical force-displacement curves indicating the variation of total, shaft and base capacity for the DE2 $(\mu=0.5)$.

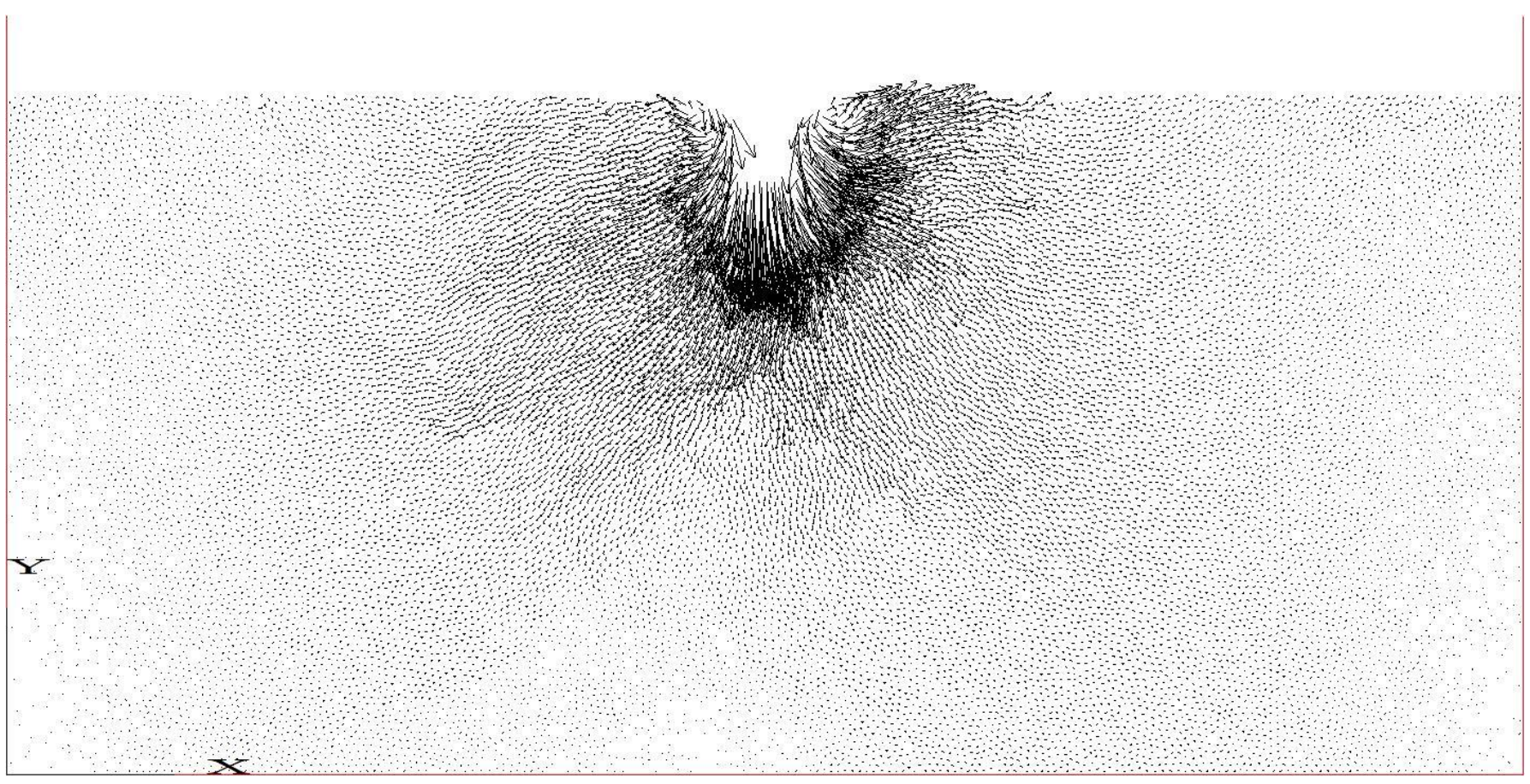

(a) 


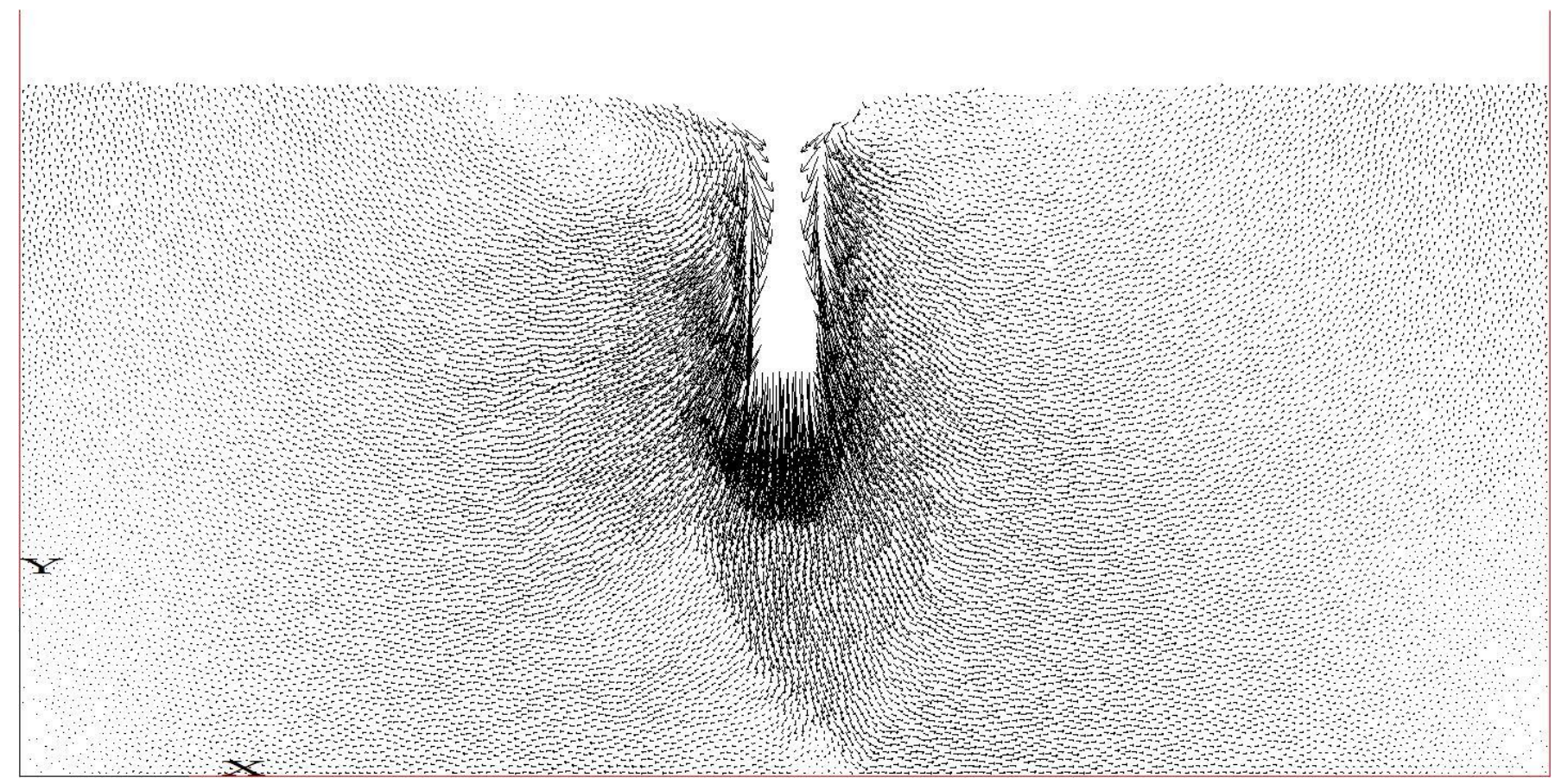

(b)

Figure 5. The vector distribution of particles displacements in DE2 case, (a) F=40 kN. (b) F=140 kN.

Figure 5 shows the incremental particle displacement vectors when the applied force reaches $40 \mathrm{kN}\left(y / d_{\text {pile }}\right.$ $=1.9)$ and $140 \mathrm{kN}\left(y / d_{\text {pile }}=4.82\right)$. The starting point of each arrow is the original location of a particle, and the end of arrow is the new location of same particle. In Figure 5 (b) when $y / d_{\text {pile }}$ is large, we find that most of the particles near the pile always move inward and settle, whereas the particles of further away from pile spread outwards. However, in Figure 5 (a) when $y / d_{\text {pile }}$ is small, the particles near the pile move more laterally and upwards compared to Figure 5 (b). This means that, the particles at the surface layer around pile initially move outward and dilate, as the applied load increases, these particles at the same location becomes relatively more static, implying there is a reduction in the zone of influence as pile penetrates. Figure 5 (b) also shows that the tip of the particles movement almost reaches the bottom space. 


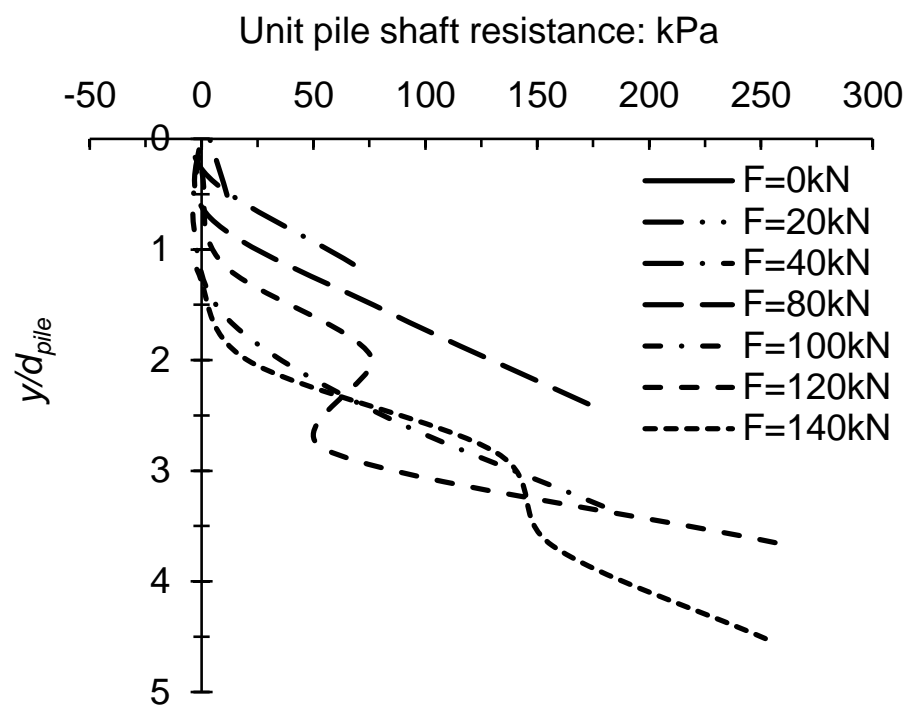

Figure 6. Unit shaft resistance along the pile at different installation depths (DE2).

The shaft resistance of Figure 4 (b), on the other hand, increases much more gently than the base resistance, and even experience some drops during driving. This implies that the unit shaft resistance may possibly decrease as the area of pile-soil contact increases during penetration. This is testified by the profile of unit shaft resistance at different vertical forces, as shown in Figure 6. Regarding the calculation of unit shaft resistance, the first step was the calculation of shaft resistance. The pile was divided into several parts, and the shaft resistance of according part was calculated from the contact force (vertical direction). Then the shaft resistance of every part of pile was divided by the accordingly length of pile. Figure 6 shows that sometimes the unit shaft resistance becomes negatives, which means the applied shaft resistance on pile surface is acting downwards. This phenomenon could come from arching effect and particles size effect. When arching is generated, the sand particles within in the range of arching do not support vertical load but only self-weight. For the particles in touch with the pile shaft, fiction is bigger than self-weight. So this phenomenon of shaft resistance causes the particles to move down with the pile. 
Level 1: Depth $=0.0924 \mathrm{~m}$

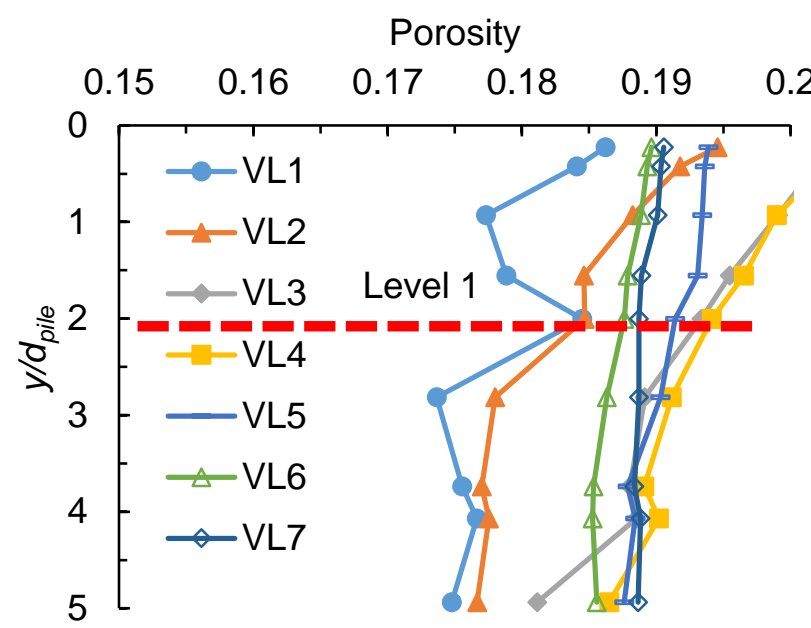

(a)

Level 2: Depth $=0.1424 \mathrm{~m}$

Porosity

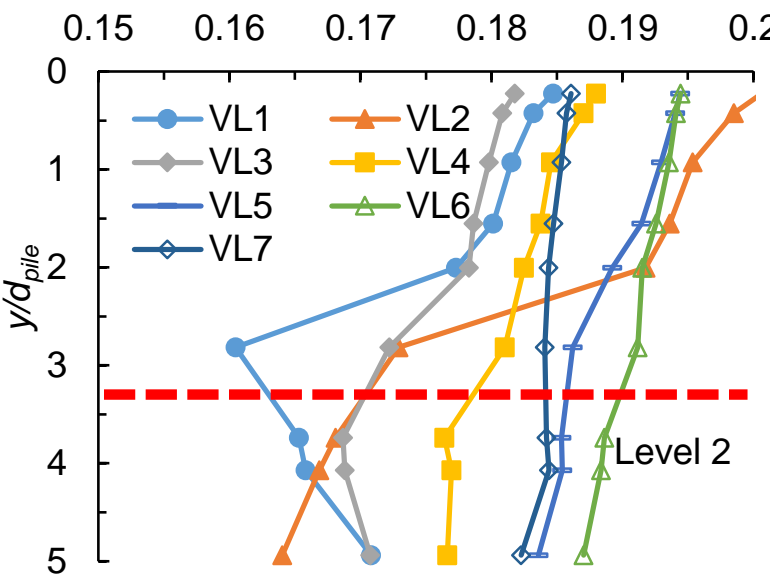

(b)

Level 3: Depth $=0.1924 \mathrm{~m}$

Porosity

Level 4: Depth $=0.2924 \mathrm{~m}$

Porosity

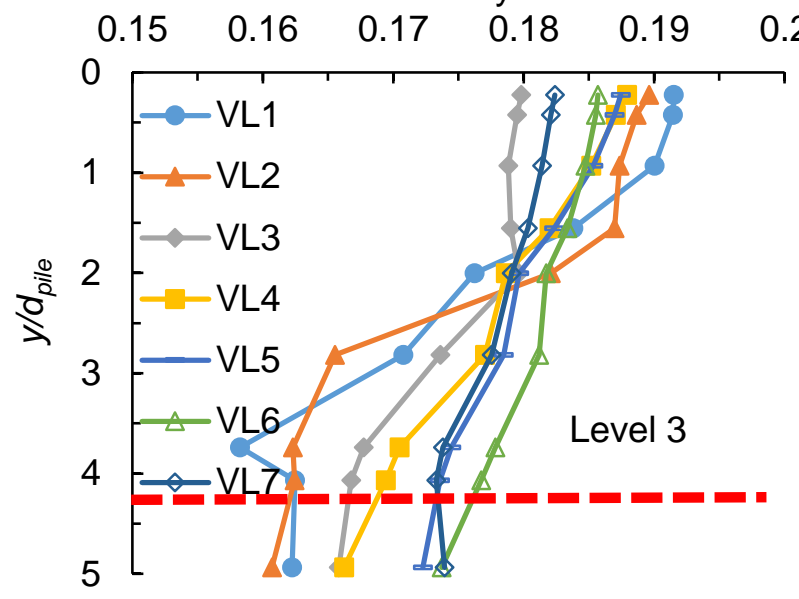

(c)

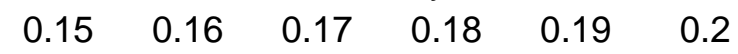

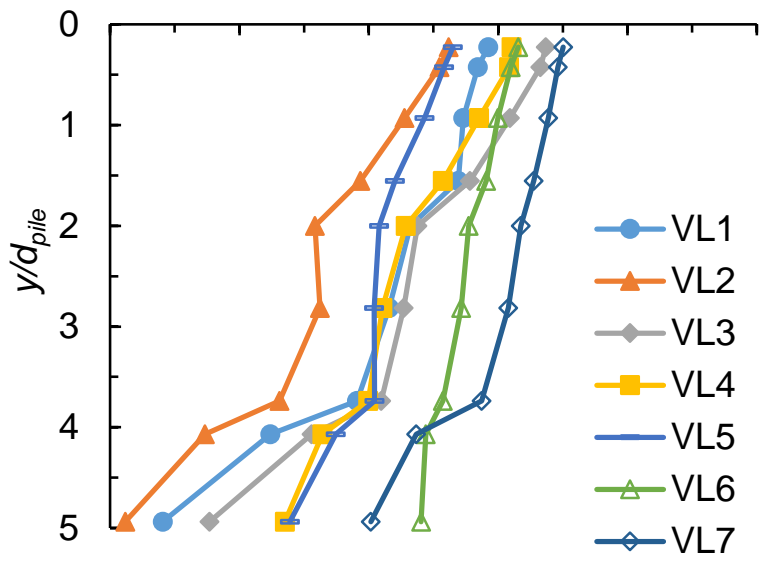

(d)

Figure 7. Porosity in measurement circle at different levels (level 1, level 2, level 3 and level 4) during the penetration of driven pile in DEM model (DE2).

Figure 7 shows the variation of porosity at four specific depths, the locations was marked in Figure 1, when the pile was penetrated to specific depth normalised by pile diameter, $y / d_{\text {pile. }}$. The data in the figure was tracked from fixed locations, using a large numbers of fixed measurement circles in the simulation. For example, in the Figure 7 (a), level 1 did not mean the data was recorded when the pile tip reach at the level 1, but level 1 showed the depth of measurement circle located level 1. Symbol of VL1 showed the vertical location of measurement circle reached at VL1 (see Figure 1). Each dot of VL1 line (blue line) meant the pile tip depth (in the figure: $y / d_{\text {pile }}$ ) as the data was recorded. The same method of track data was used in following figures (such as Figure 8, 10, 14 and 15). From the trend of Figure 7, the porosity distribution 
during the penetration of driven pile are shown. This mainly attributes to the volume reduction of the soil as the sand grains rearrange and repack surrounding the pile, which is captured in this simulation. From these figures, the porosity at the surface layer had a degree of variation. Because the state of surface layer was relative loose, the particles could move due to the disturbance. However, the variation is less as the depth went to deeper. The data of these figures also show that the shallow layer changed to relative loose state due to the penetration of pile. On the contrary, the deep layer transferred to the dense state because of the extrusion.

In Figure 8, the changes of lateral stresses recorded in surrounding soil during the pile penetration are shown. This also can connect to the volume reduction of the soil (Figure 7). Figure 8 shows the lateral soil stresses at 4 specific depths (e.g. Figure 8 (a): Level 1 at the shallowest depth, and Figure 8 (d): Level 4 at the deepest depth) and different distances away from the pile (VL1-VL10) while the pile tip has penetrated to different normalised depth $\left(y / d_{\text {pile }}\right)$. This is clear in Figure 8 (a) that the lateral stress on the pile-soil interface reduces drastically and close to the initial $K_{0}$ stresses after pile tip passes by.

The changes of lateral stresses recorded in surrounding soil during the pile penetration are shown in Figure 8. At levels 1-3 above the pile tip, the general variation of lateral stress displayed a similar tendency and matched the penetration process fairly well. As the pile tip penetrated the soil and advanced down, the lateral stresses increase sharply as a result of large soil deformation. This phenomenon follows the illustration of F. Yu (2004) and Liu et al. (2012) that a penetrating pile base resembles the expansion of a spherical cavity. In the close regions from the pile shaft, the lateral stresses increase sharply and reach peak values as the pile tip almost penetrate to the level of these locations, and then decreased as the pile tip penetrated deeper. Similar trends of the variation in lateral stress have also been observed in centrifugal model tests (Leung, Lee, \& Yet, 2001; Yang, Jardine, Zhu, \& Rimoy, 2013) and field tests (Liu et al., 2012).

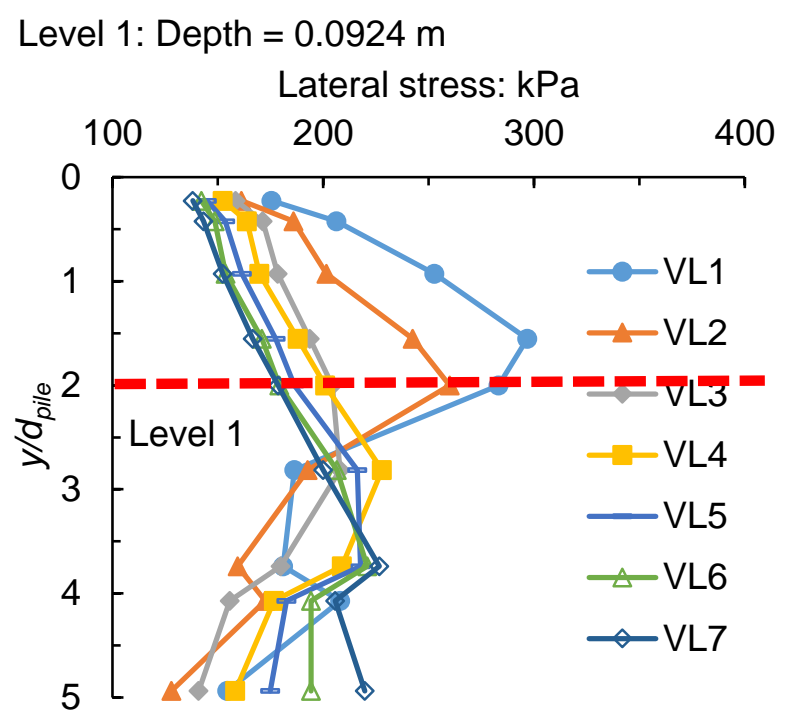

Level 2: Depth $=0.1424 \mathrm{~m}$

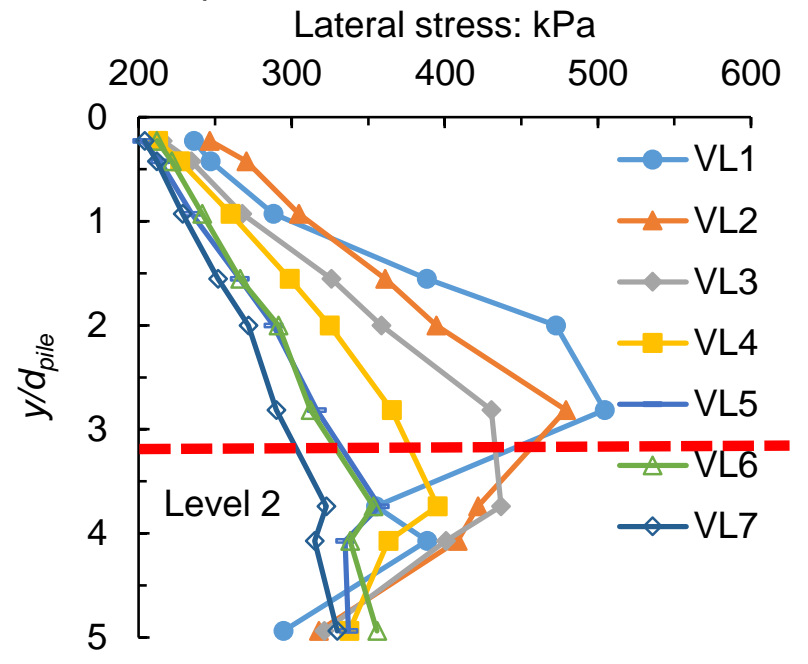


(a)

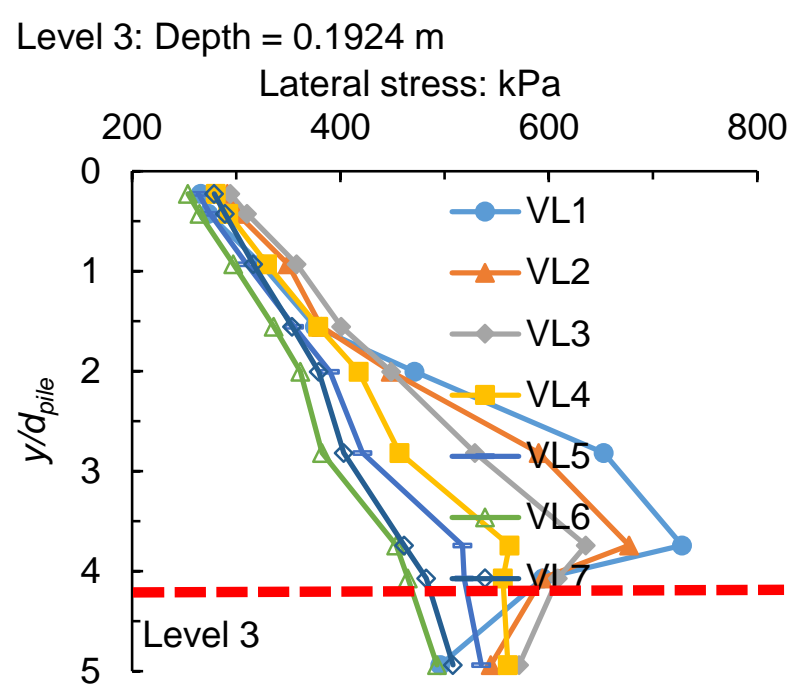

(c) (b)

Level 4: Depth $=0.2924 \mathrm{~m}$

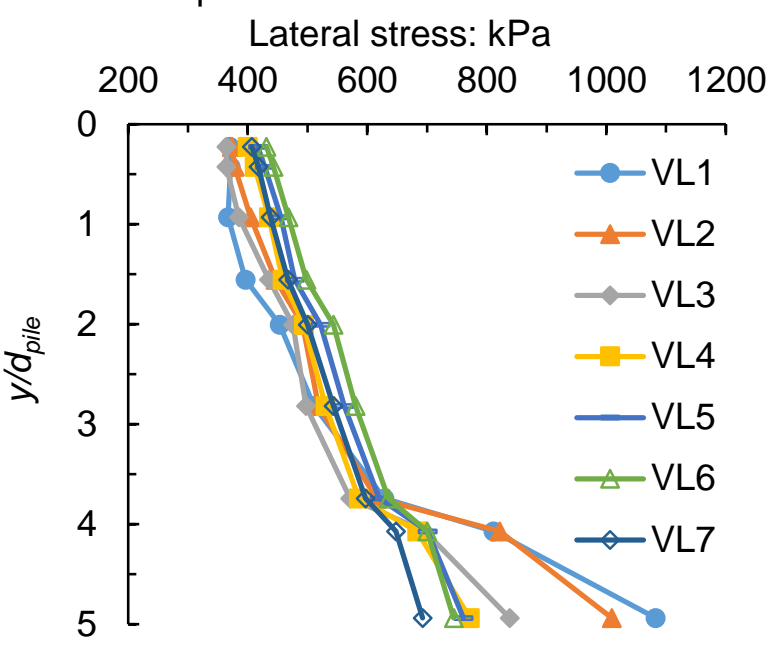

(d)

Figure 8. Lateral stress in measurement circle at different levels (level 1, level 2, level 3 and level 4) during the penetration of driven pile in DEM model (DE2).

The greatest percentage increase of induced lateral stress was registered by level 3 at the full embedment depth $(\sim 0.2 \mathrm{~m})$, which is $48 \%$ and $173 \%$ greater than those by level 2 and level 1, respectively. This observation indicates that the magnitude of the induced lateral stress depends not only on the radial distance but also on the embedment depth or the overburden pressure. Hence, the ratio of the increases of lateral stress $\left(\Delta \sigma_{\mathrm{h}}\right)$ to the initial horizontal $K_{0}$ stresses $\left(\sigma_{0}\right)$ against the normalized horizontal distances are plotted for all the three levels in Figure 9. It is clear that the curves corresponding to the three levels seemed to exhibit similar distribution, and restricted in an approximately logarithmic distribution zonal region. Then an effecting region of 12 18 pile diameters from pile shaft can be confirmed according to the enveloping lines. This region is consistent with the experimental observations by Yang et al. (2013) and field tests Liu et al. (2012). 


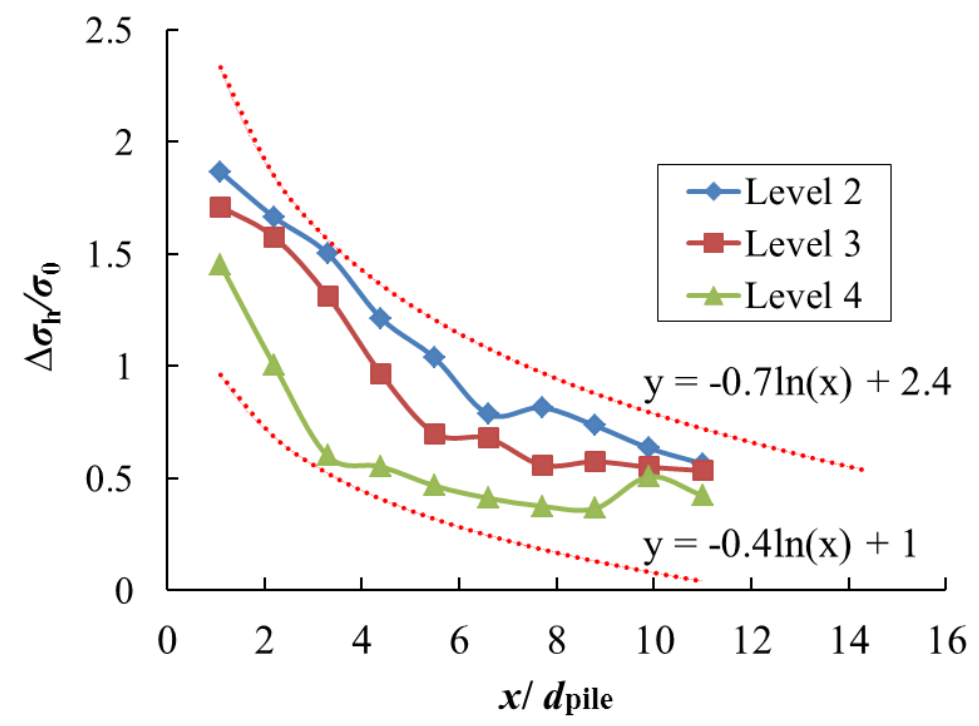

Figure 9. Variation in normalized maximum increase of lateral stress with normalized horizontal distance (DE2).

For level 4, which is $2.2 d_{\text {pile }}$ lower than the final depth of pile tip, the lateral stresses build up gently for each record point. For the farthest VL7 (see Figure 8 (d)) that is $7.77 d_{\text {pile }}$ from pile shaft, no evident change is recorded at the beginning penetration. This means the obvious affecting distance of pile driving was approximately less $7.77 d_{\text {pile, }}$, which is in the range obtained from Figure 9.

In Figure 10, the $\mathrm{x}$-axis was normalised by $x / d_{\text {pile }}$ which means the according lateral distance from the left side of pile. 0 means the left surface of pile. When the pile tip was just pushed to the depth level 1 (see Figure 10 (a)), the area of $x / d_{\text {pile }}<3$ was the first domain which will be affected. The peak value of lateral stress was reached when the vertical force only achieved about 40-60 kN. Then the lateral stress where near the pile was decreased. The level 3 (see Figure 10 (b)) is a little deeper than level 2 and the peak value was appeared when the applied force was $80 \mathrm{kN}$. For the level 2 (see Figure 10 (c)) which is around the pile bottom and much deeper. Therefor the lateral stress maximum value attained when the applied force is 100 $\mathrm{kN}$. Level 1 (see Figure 10 (d)) is very deep, so the lateral stress keeps increasing. 
Level 1: Depth $=0.0924: \mathrm{m}$

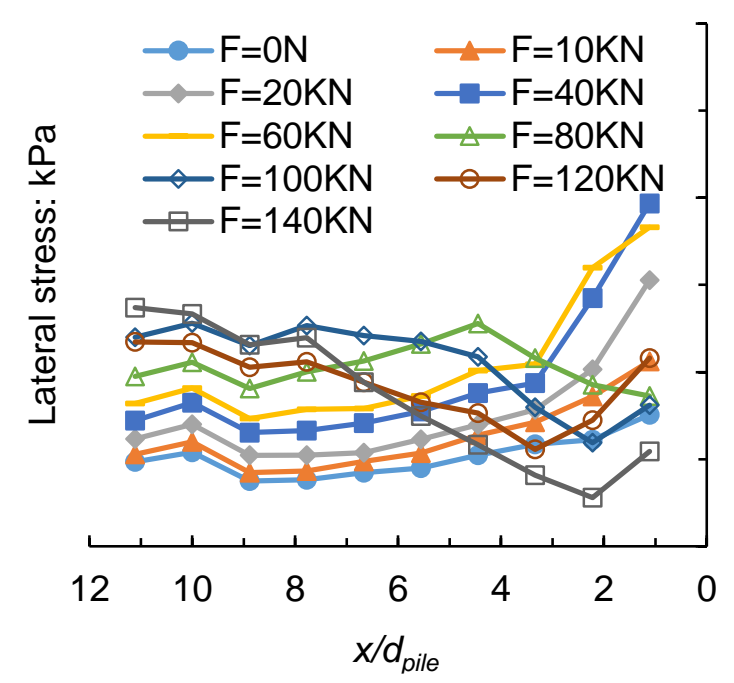

(a)

Level 3: Depth $=0.1924: \mathrm{m}$

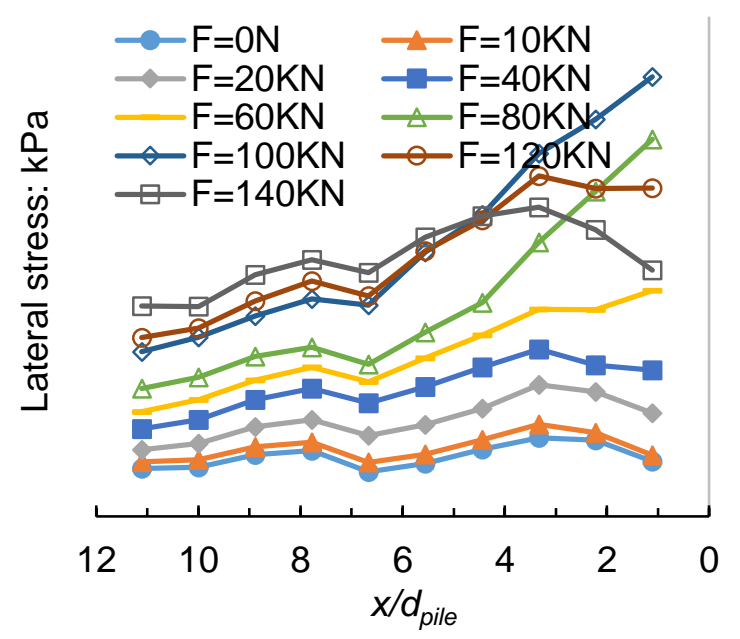

(c)
Level 2: Depth $=0.1424: \mathrm{m}$
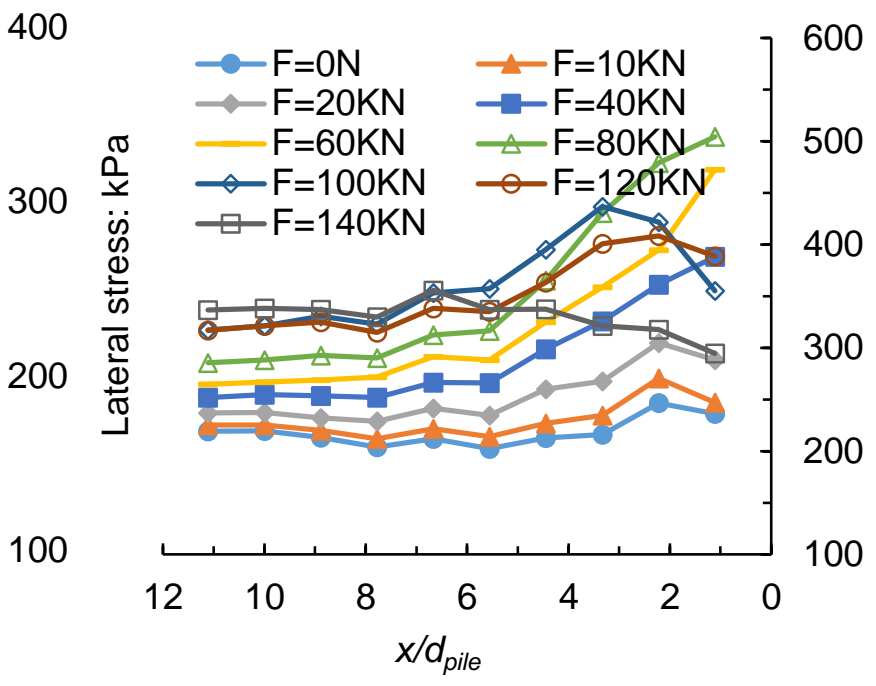

(b)

Level 4: Depth $=0.2924: \mathrm{m}$

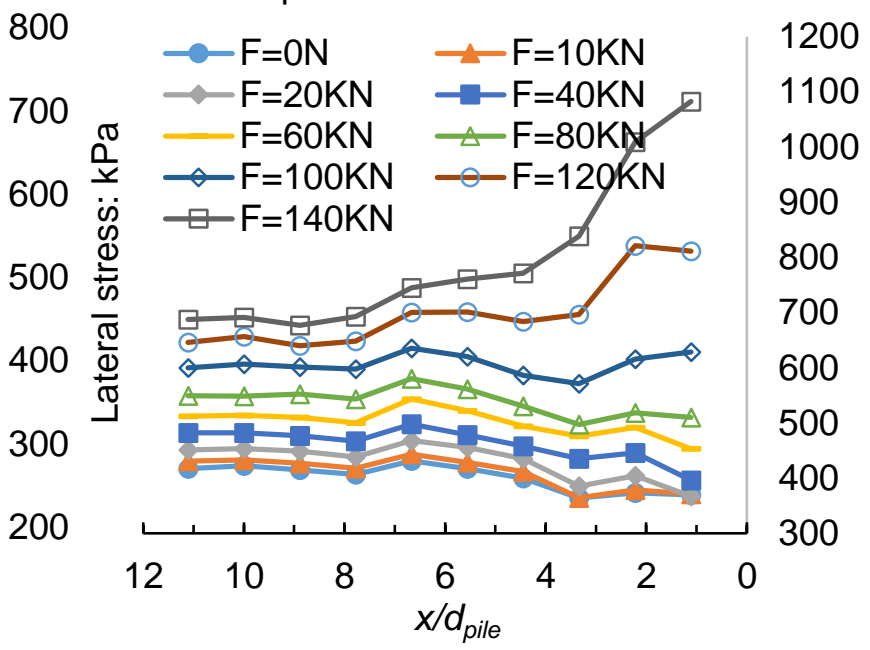

(d)

Figure 10. Lateral stress in measurement circle at different levels (level 1, level 2, level 3 and level 4) during the procedure of driven pile in DEM model (DE2).

\subsection{Bored pile}

The model generation procedure of a bored pile is simpler compare to that of a driven pile. Part of the soil was first deleted before the bored pile was put in the soil, the pile was then generated and the model kept cycling until equilibrium. Figure 11 (a) shows the load-settlement curves of the bored pile after the pile is installed, and the corresponding mobilised shaft resistance against settlement curves in Figure 11 (b), during pile load test for piles (Cases 01-04) having different weights. Although the load-settlement curves are different, with the heaviest pile settles significantly more, the development of shaft resistance look 
generally similar reaching a similar maximum value of around $20 \mathrm{KN}$. It should be noted however that the initial shaft resistance of different piles are not exactly the same (see Figure 11 (b)) but light pile experiences negative initial shaft resistance while heavy pile experiences positive and high initial shaft resistance. Due to this phenomenon, Case 03 pile (03_BE_2) was chosen. Figure 12 shows the effect of soil friction coefficient to the load-settlement curves for total vertical load (Figure 12 (a)) and for shaft resistance (Figure 12 (b)) for case 03. From Figure 12(a), the pile settlement of low soil friction was more obvious when the vertical load became larger. Moreover, when the friction of particle is bigger, the line remains more linear. This linear range indicates that friction has not been fully mobilised fully throughout the pile hence smaller percentage of sliding between the pile surface and adjacent soil particles occurs. As more and more particle sliding happens, shaft resistance becomes constant even if vertical load increases.

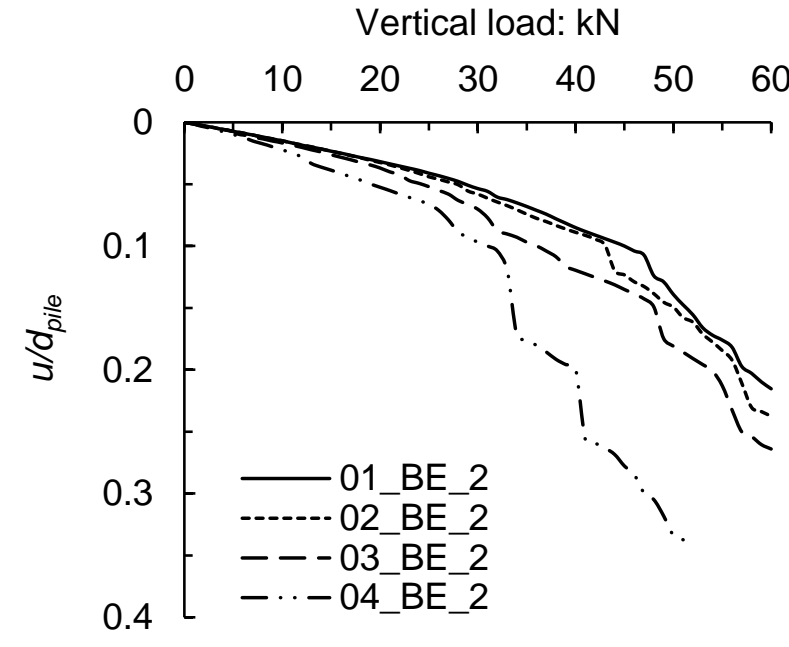

(a)

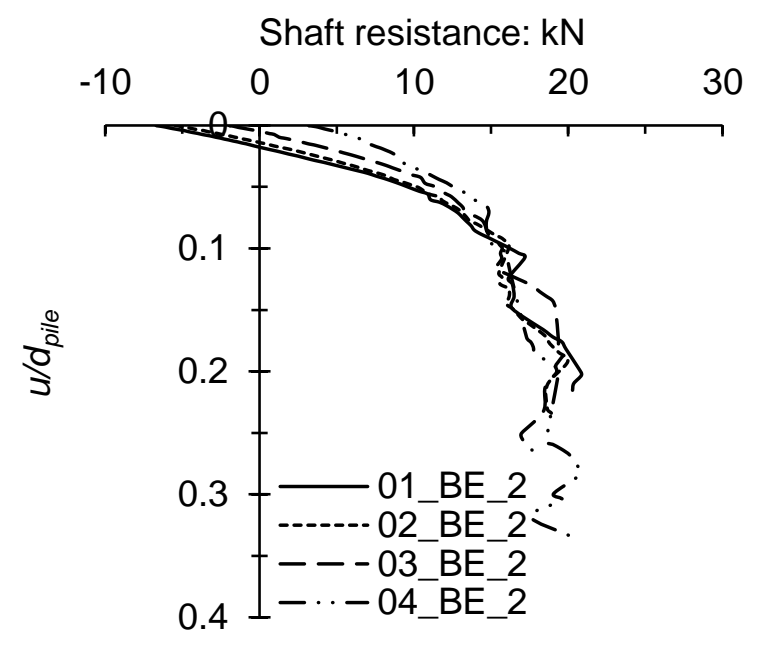

(b)

Figure 11. Comparison of load-settlement curves with pile having different weights (ratio of pile weight over displace soil weight, Case 01=6.74\%, Case 02=20.22\%, Case 03=50.55\%, and Case 04=101.11\%). 


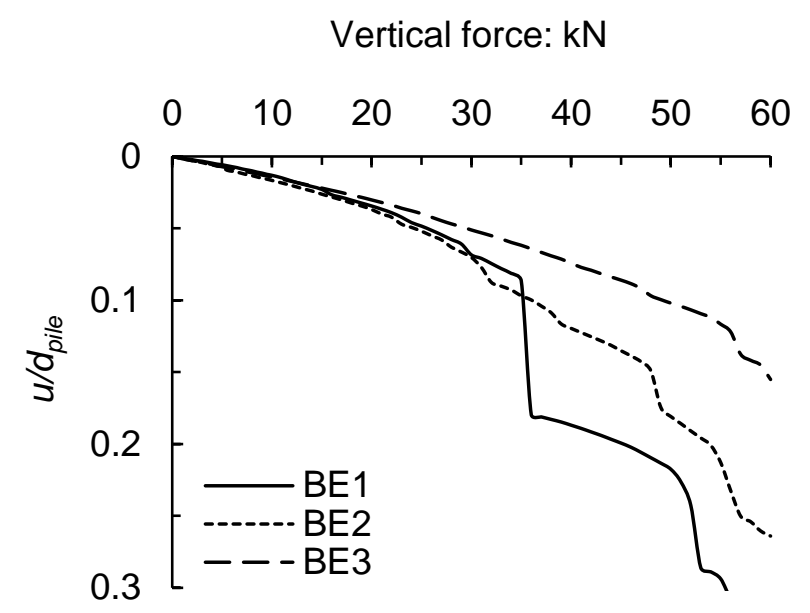

(a)

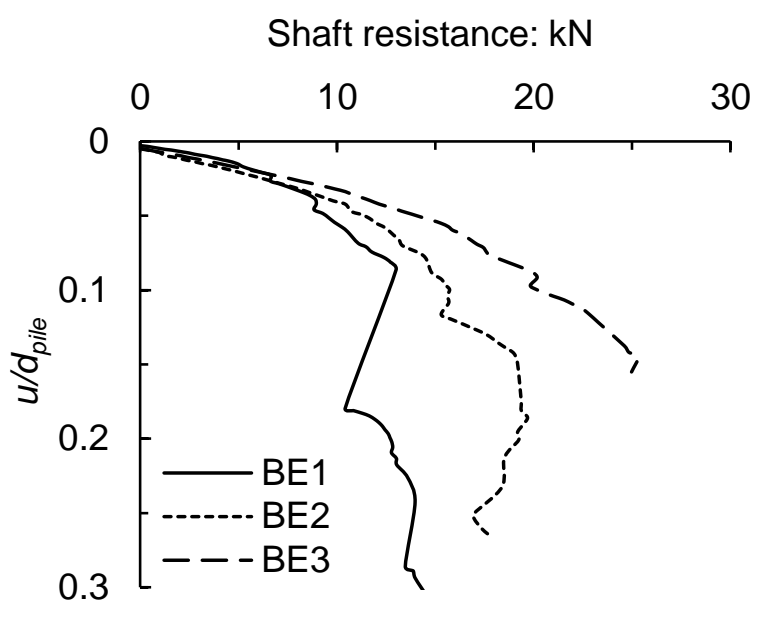

(b)

Figure 12. Comparison of load-settlement and shaft resistance-settlement curves of bored pile in different soil conditions $(\mu=0.2,0.5 \& 0.8)$.

\section{Comparison and discussion}

The initial states are important when compare these two types. For the bored pile, the final pile embedded depth is easy to control, however, the driven pile will cause the springback. The initial embedded depth of pile should be the same when the tests of comparison are beginning to proceed. It should be noted here is, the pile was finally driven to the depth that is a little more than $0.2 \mathrm{~m}$ depth $(0.2007 \mathrm{~m}, 0.2015 \mathrm{~m}, 0.2024 \mathrm{~m}$ for DE1, DE2 and DE3, respectively). This is to allow for the pile moving upwards slightly to a final $0.2 \mathrm{~m}$ depth after the applied force was released. This phenomenon is considered to be the cause of residual force in driven pile (Liu, Yu, Zhang, \& Wang, 2013; L. M. Zhang \& Wang, 2007, 2009).

\subsection{The bearing properties}

Figure 13 presents the comparison of total load-settlement curves with different installation methods. Due to the different installation methods, the driven pile caused higher vertical capacity than the bored pile. When the vertical load is less than $25 \mathrm{kN}$, the curves below exhibit nearly the same trend for both piles. However, the bored pile goes deeper into the soil at a faster rate with the same load after this point, showing that bored piles cause further vertical displacement. 


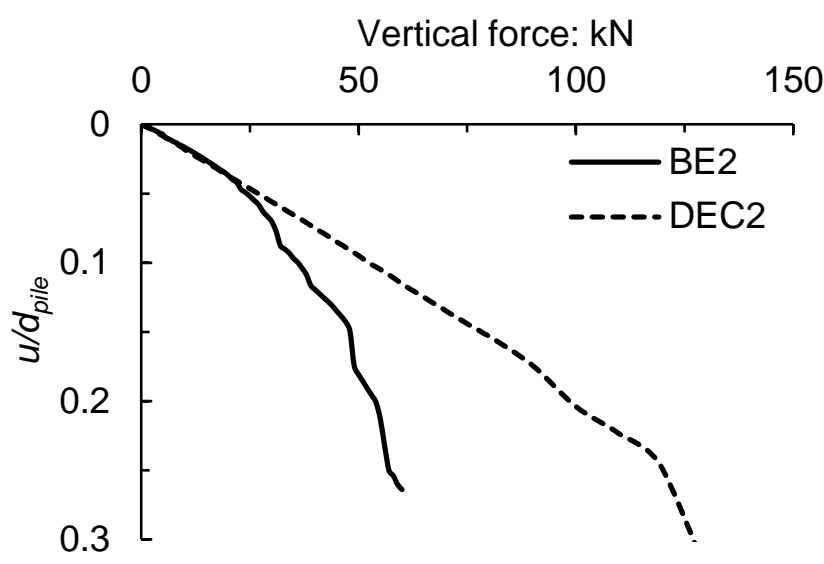

Figure 13. Comparison of load-settlement curve with different installation.

Figure 14 shows the comparison of loading test, the $\mathrm{x}$-axis was normalised by $x / d_{\text {pile }}$ which was similar to Figure 10. When the pile embedded length was just pushed to depth level 1 (see Figure 14 (a) and (b)) which was the first domain which will be affected. This level is relative shallow. Regrading to the level 2 (see Figure 14 (c) and (d)), For the bored pile (see Figure 14 (c)), the peak value of lateral stress was reached when the vertical force achieved about $140 \mathrm{kN}$. However, in term of driven pile the peak value of lateral stress was reached when the vertical force only achieved about $120 \mathrm{kN}$. Then the lateral stress where near the pile was decreased. The level 3 (see Figure 14 (e) and (f)) is a little deeper than level 2, and the phenomenon also were same. For the level 3 which is around the pile bottom and much deeper. Level 4 (see Figure $14(\mathrm{~g})$ and $(\mathrm{h}))$ is very deep, so the lateral stress keeps increasing.

Concerning the lateral stress of bored and driven pile, obviously the driven pile is larger than the corresponding deep level bored pile. This relationship also can be indicated from the Figure 13.

Level 1: Depth $=0.0924 \mathrm{~m}$

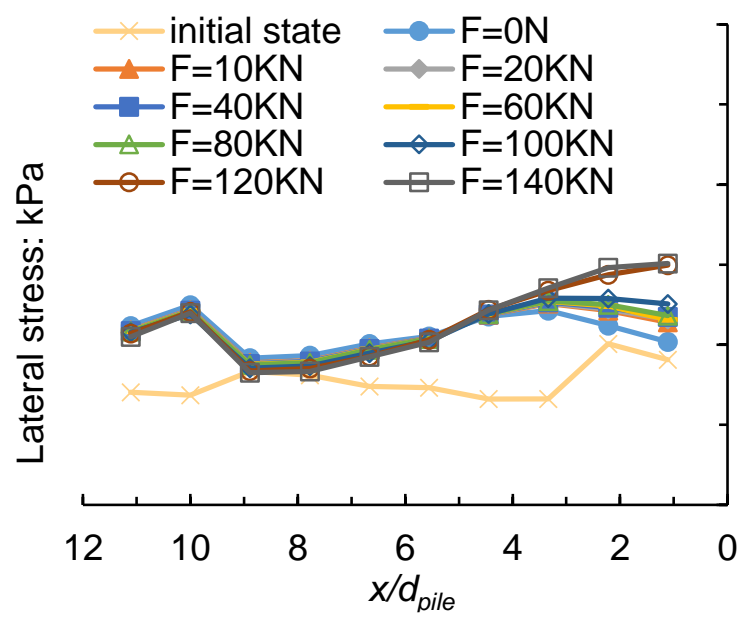

Level 1: Depth $=0.0924 \mathrm{~m}$
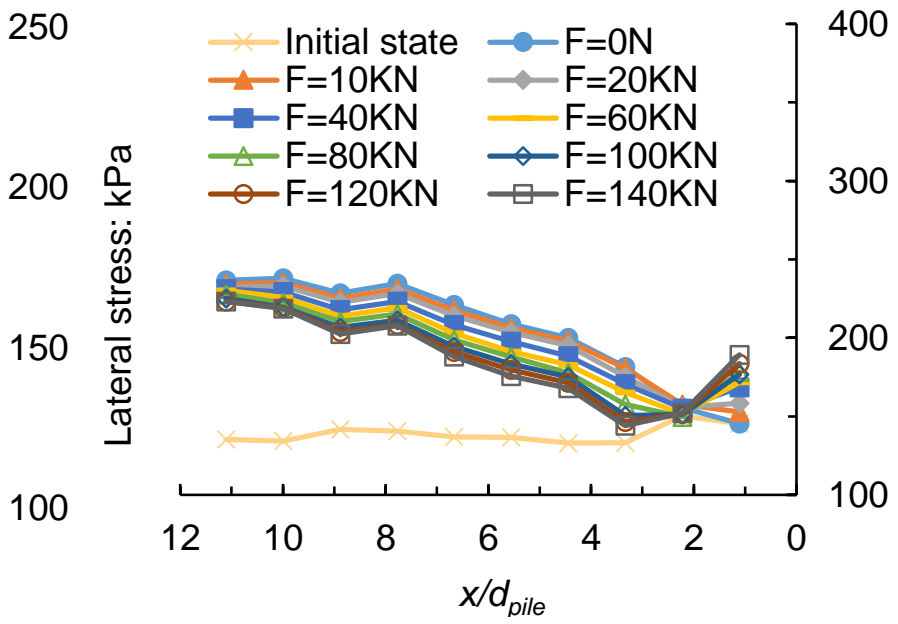

Page 22 
Level 2: Depth $=0.1424 \mathrm{~m}$

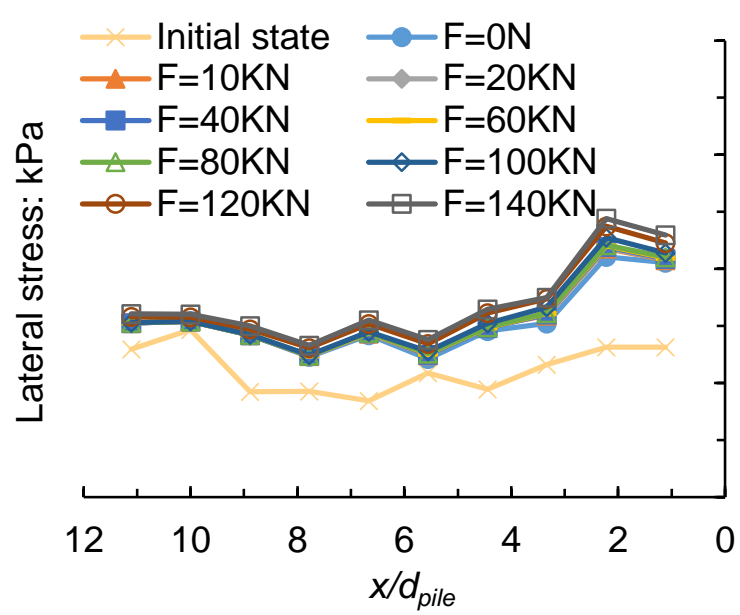

(c)

Level 2: Depth $=0.1424 \mathrm{~m}$

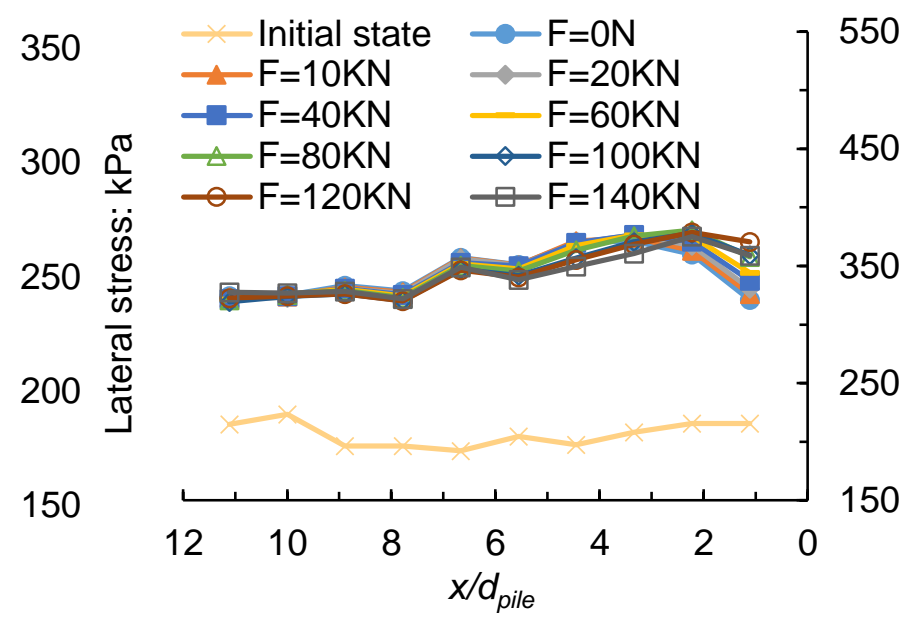

(d)

Level 3: Depth $=0.1924 \mathrm{~m}$

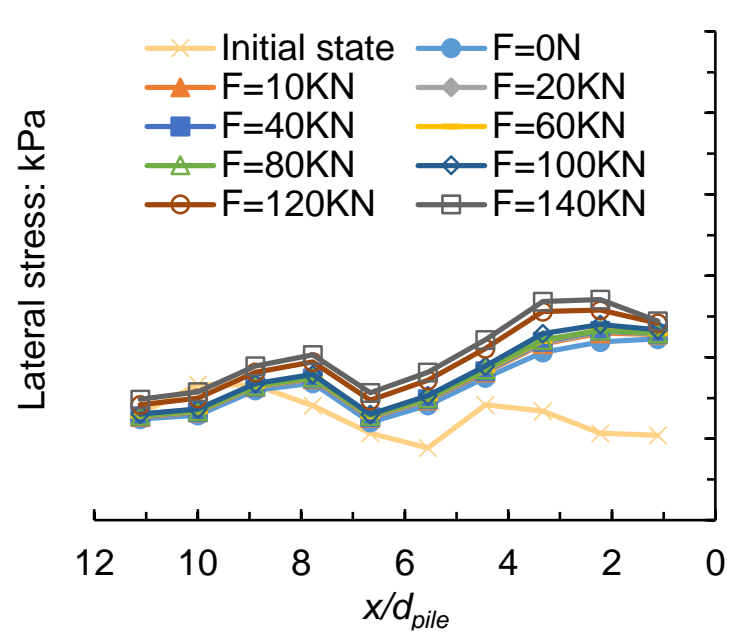

(e)

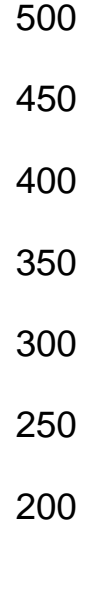

500
450
400
350
300
250
200

Level 4: Depth $=0.2924 \mathrm{~m}$

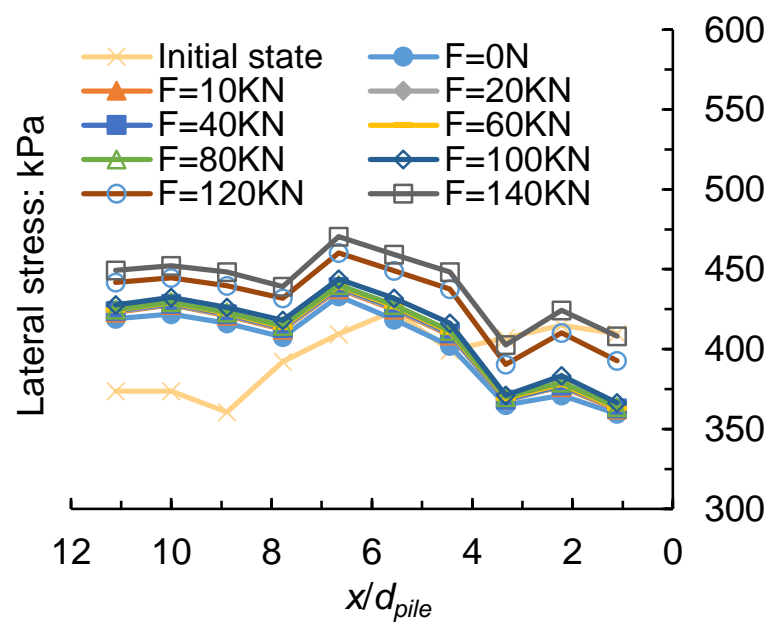

Level 3:Depth $=0.1924 \mathrm{~m}$

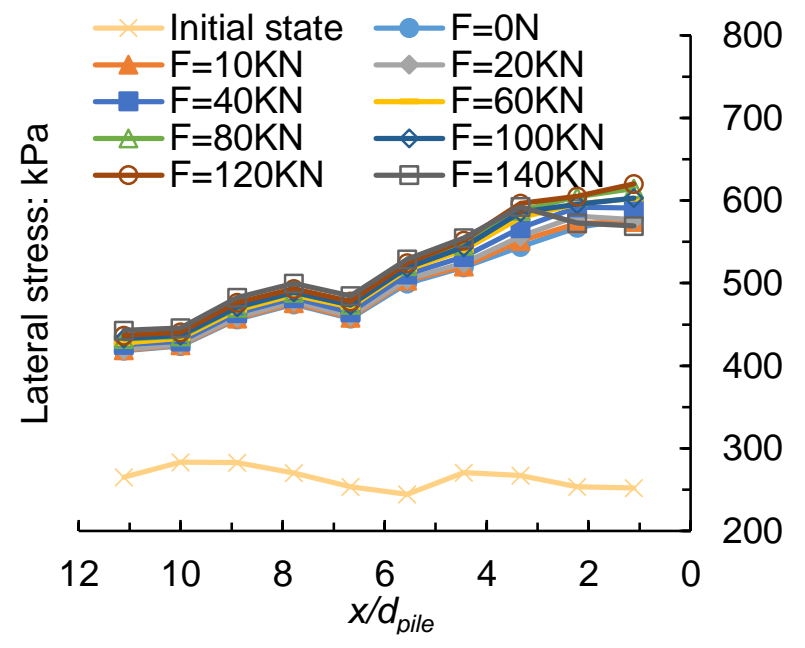

(f)

Level 4: Depth $=0.2924 \mathrm{~m}$

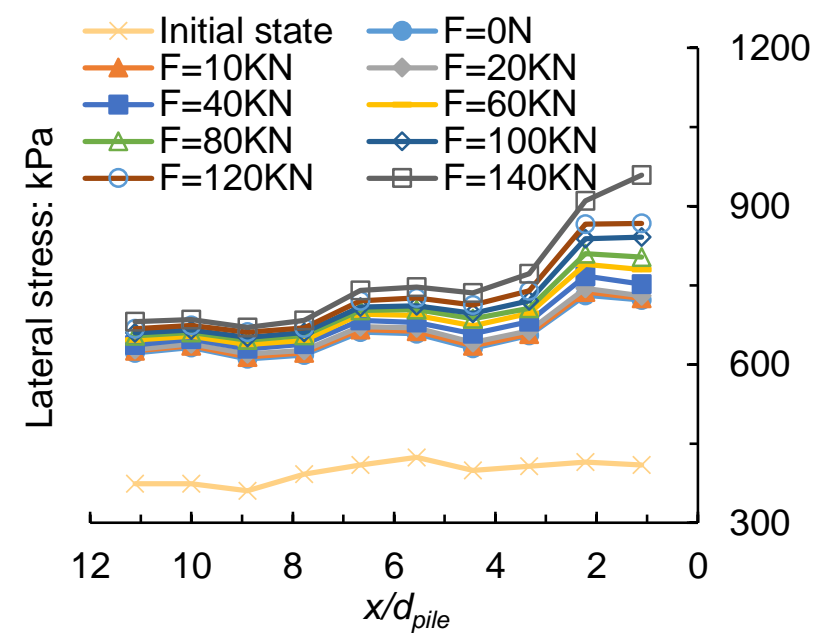

Page 23 
Figure 14. Lateral stress in measurement circle at different levels (level 1, level 2, level 3 and level 4) at horizontal direction, $(a)(c)(e)(g)$ : bored pile; $(b)(d)(f)(h)$ : driven pile.

\subsection{Sliding fraction}

The sliding fraction is the fraction of physical contacts within a measurement circle that have shear forces within $0.1 \%$ of the limiting shear force.

From the Figure 15, the initial state means the particles are static state, as a result, the sliding fraction of initial state is 0 . However, the pile still has the self-weight when the applied vertical force is $0 \mathrm{~N}$.

At the shallow location of measurement (level 1), the sliding fraction states of bored and driven pile are similar when the applied force is smaller than $100 \mathrm{kN}$ (see Figure 15 (a), (b)). As the applied force increases, the sliding fraction of area near driven pile is decreasing, however, the sliding fraction of far area from driven pile is increasing quickly.

When the applied force is bigger than $100 \mathrm{kN}$, the sliding fraction of neighbourhood near bored pile increase quickly which means the surrounding sands are moving. The sliding fraction of far area from driven pile $\left(x / d_{\text {pile }}>=6\right)$ is growing all the time, because the surrounding area of driven pile had been extruded when the pile was just pushed to the soil, so the maximum of skid resistance capacity was early reached and the sands were compacted. When the applied force is increasing, the pile is squeezing the surrounding sands. Then the circumambient sands of pile would move far from the pile.

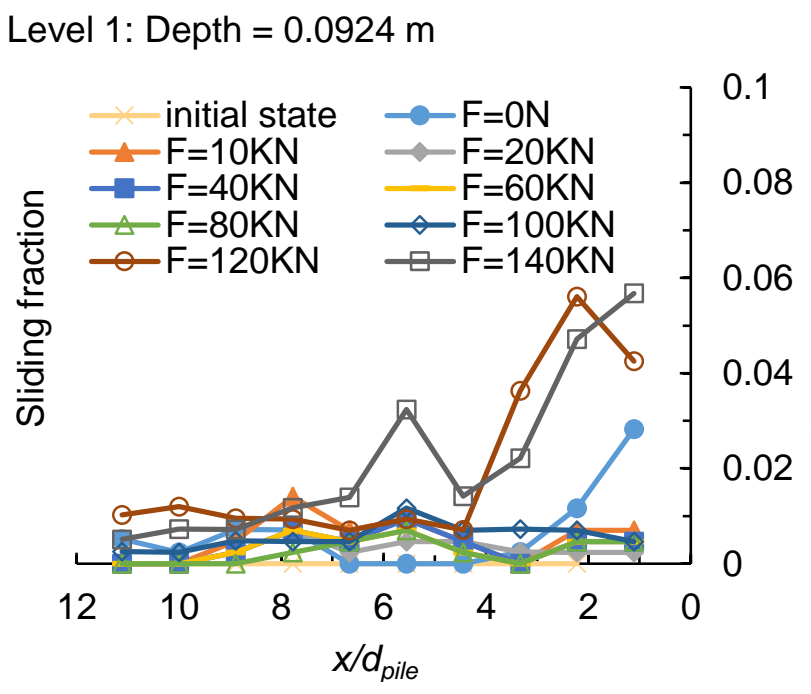

(a)
Level 1: Depth $=0.0924 \mathrm{~m}$

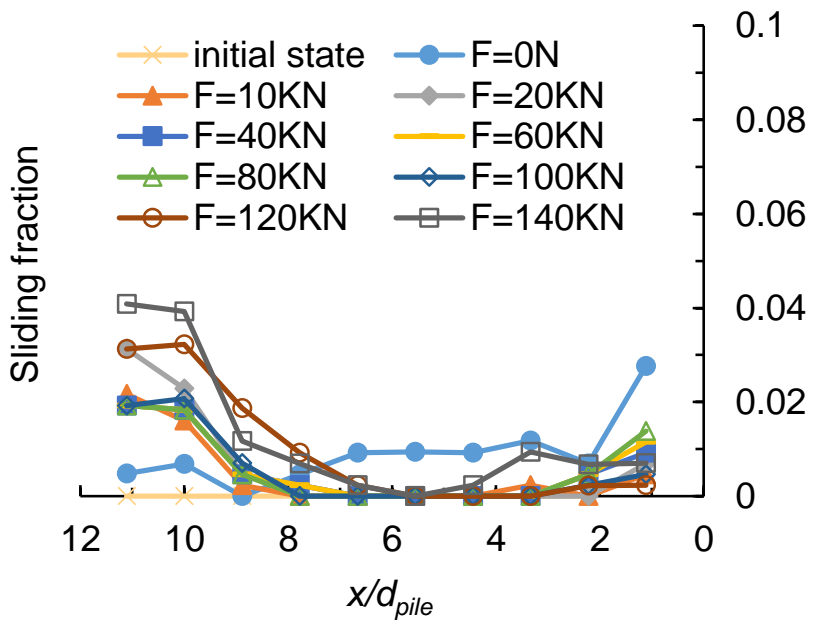

(b) 
Level 2: Depth $=0.1424 \mathrm{~m}$

Level 2: Depth $=0.1424 \mathrm{~m}$

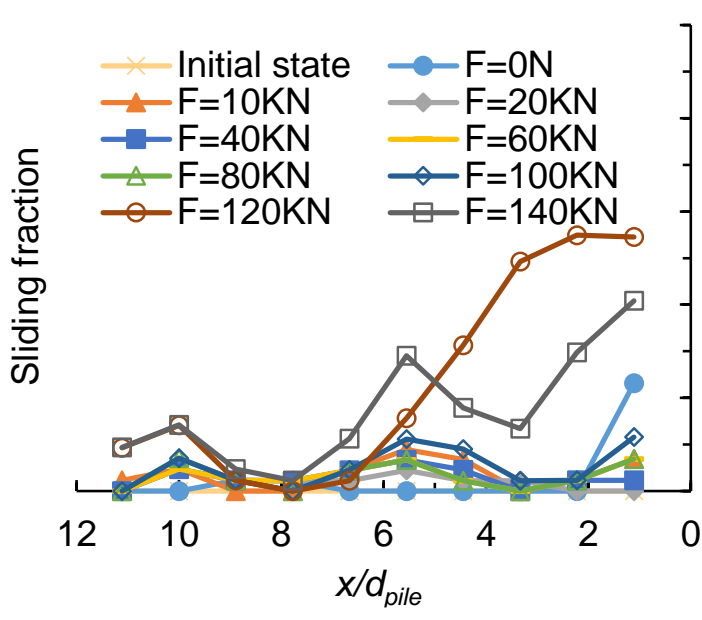

(c)

Level 3: Depth $=0.1924 \mathrm{~m}$

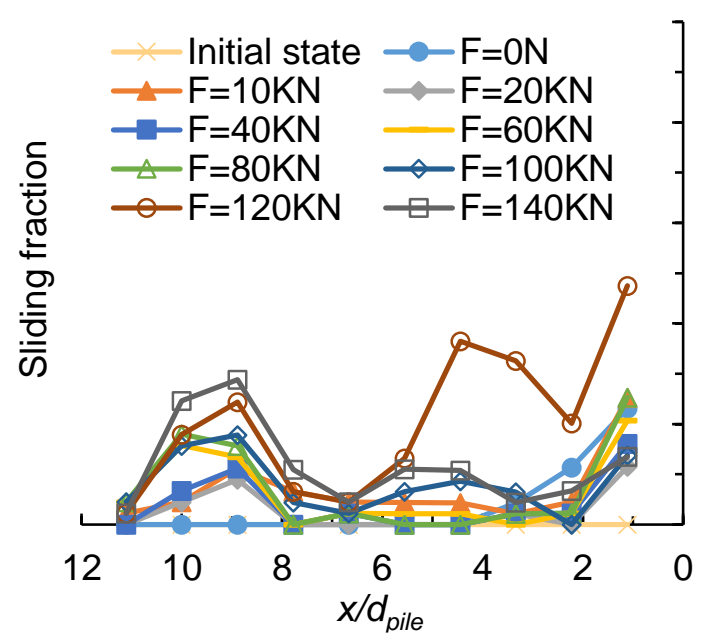

(e)

Level 4: Depth $=0.2924 \mathrm{~m}$

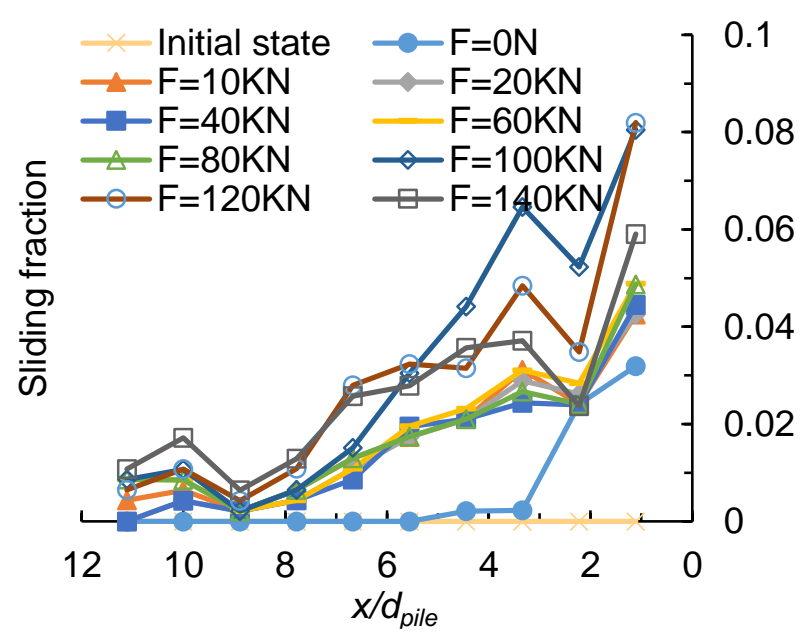

(g)

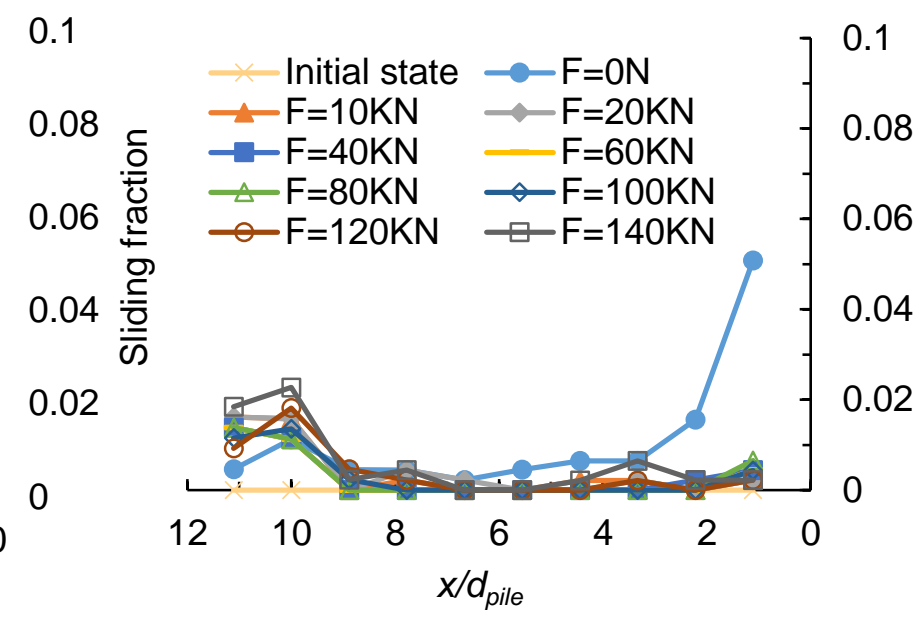

(d)

Level 3: Depth $=0.1924 \mathrm{~m}$
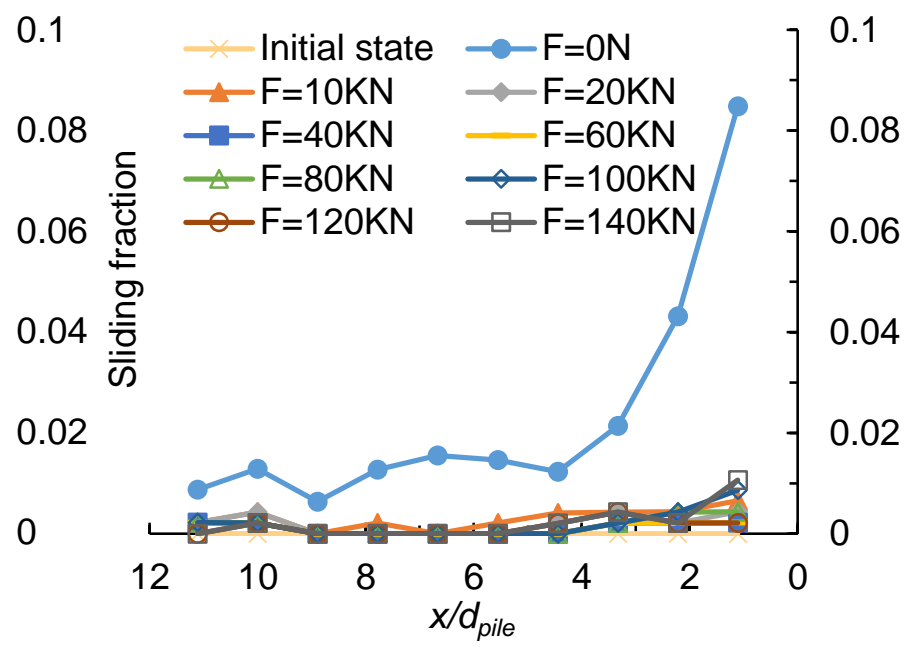

(f)

Level 4: Depth $=0.2924 \mathrm{~m}$

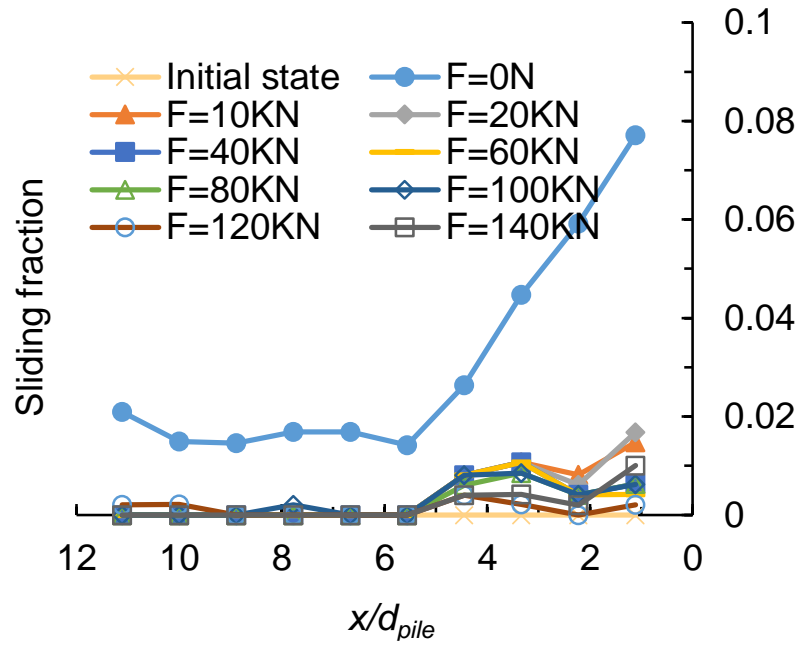

(h) 
Figure 15. Sliding fraction in measurement circle at different levels (level 1, level 2, level 3 and level 4) at horizontal direction with different installation, bored pile: $(a)(c)(e)(g)$; driven pile: $(b)(d)(f)(h)$.

From the Figure $15(\mathrm{~g})$, the sliding fraction value of bored pile is the biggest when the condition of applied force is only considered at $0 \mathrm{kN}$. The reason is the location of measurement, and level 4 locates under the pile tip. Also, the data prove this area is the most susceptible region. For the bored pile case, as the applied force increase, most particles of surrounding districts are sliding.

The Figure 15 (f), (h) show the high sliding fraction as the applied force is $0 \mathrm{kN}$. This is due to the pre-compaction, when the applied force was set free, the pile will appear springback. The level 4 is under the pile tip, so the sliding fraction is bigger. Regarding the driven pile case, most particles of surrounding districts are not sliding.

This comparison demonstrates that the surrounding area of driven pile has the high bearing capacity.

\subsection{Mobilisation of shaft resistance}

The mobilizations of shaft resistances of pile DE2 and BE2 during loading are shown in Figure 16. In Figure 16 (a), the negative shaft friction occurs over the full pile length before loading. This residual shaft resistance is due to the pile upward moving just after generation as the weight of pile is lighter than the deleted original soil. When the bored pile was applied the vertical force again, the movement of pile began to turn downwards, then the shaft resistance is mobilized and start to become positive. During the procedure of increasing loads, the shaft resistance is generally small at both ends but large in the middle. At the final load, the maximum unit shaft at pile bottom is $113 \mathrm{kPa}$, which is only one third of that for driven pile as shown in the Figure 16 (b).

Table 5. Driven pile rebound record.

\begin{tabular}{|l|l|l|l|l|}
\hline Test & $\begin{array}{l}\text { Initial vertical } \\
\text { load }(\mathrm{kN})\end{array}$ & $\begin{array}{l}\text { Initial depth } \\
(\mathrm{m})\end{array}$ & $\begin{array}{l}\text { Depth after } \\
\text { load release } \\
(0 \mathrm{kN})\end{array}$ & $\begin{array}{l}\text { Rebound } \\
\text { distance }(\mathrm{m})\end{array}$ \\
\hline DE1 & 116.48 & 0.210596 & 0.200756 & 0.00984 \\
\hline DE2 & 128.9 & 0.213526 & 0.201576 & 0.01195 \\
\hline DE3 & 151.4 & 0.218116 & 0.202456 & 0.01566 \\
\hline
\end{tabular}

Figure 16 (b) shows the changes in shaft resistance of DE2 during load procedure, which looks very 
different from the bored pile BE2. Although there also exist negative shaft resistances before loading, their magnitudes are much larger than that of bored pile. The residual shaft resistance exhibits an approximately linear distribution with the depth, and thus the maximum residual load is certainly located at the pile toe. This distribution is similar to those calculated by Poulos (1987) and Altaee, Evgin, and Fellenius (1992). After finishing the driving installation and releasing the load, the rebound of soil blow the pile bottom pushed the pile shaft upwards. The rebounds of these three piles are in Table 5, which are enough to reverse the direction of the unit shaft resistance from an upward direction during driving to a downward direction. With the static loads applied and with the pile DE2 settlements, the direction of shaft resistance is reversed again, and the positive shaft resistances are generally mobilised. When the load is added to $40 \mathrm{kN}$, the shaft resistance along the whole depth becomes positive. At this moment, the shaft resistance on bottom and top of the pile are nearly zero, but on the middle is as high as $58 \mathrm{kPa}$. With the increasing load, the deeper shaft resistance is further mobilised, and reach to the peak value of $350 \mathrm{kPa}$ at the final load. This value is closed to the recommended value for dense sand in the Chinese pile design code (JGJ 94-2008, 2008).

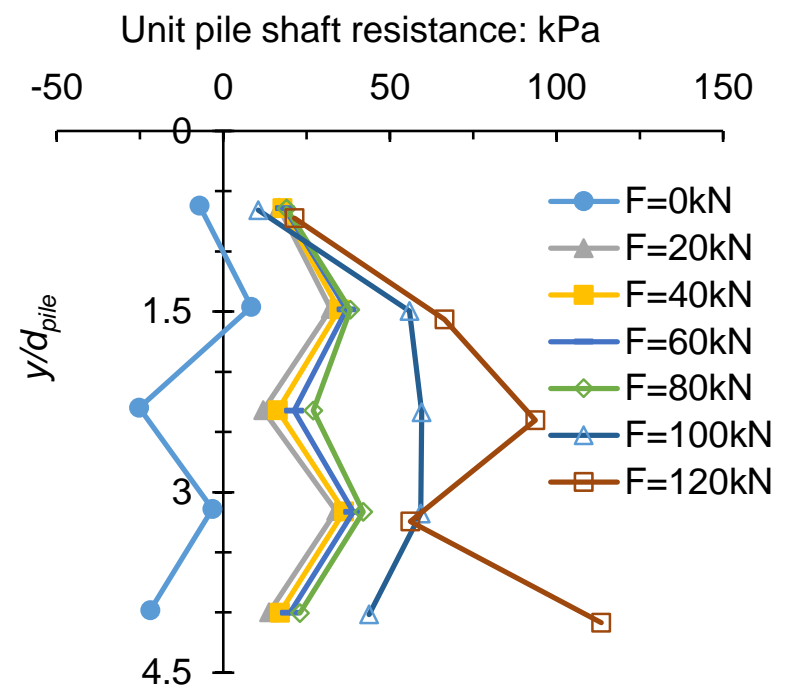

(a)
Unit pile shaft resistance: $\mathrm{kPa}$

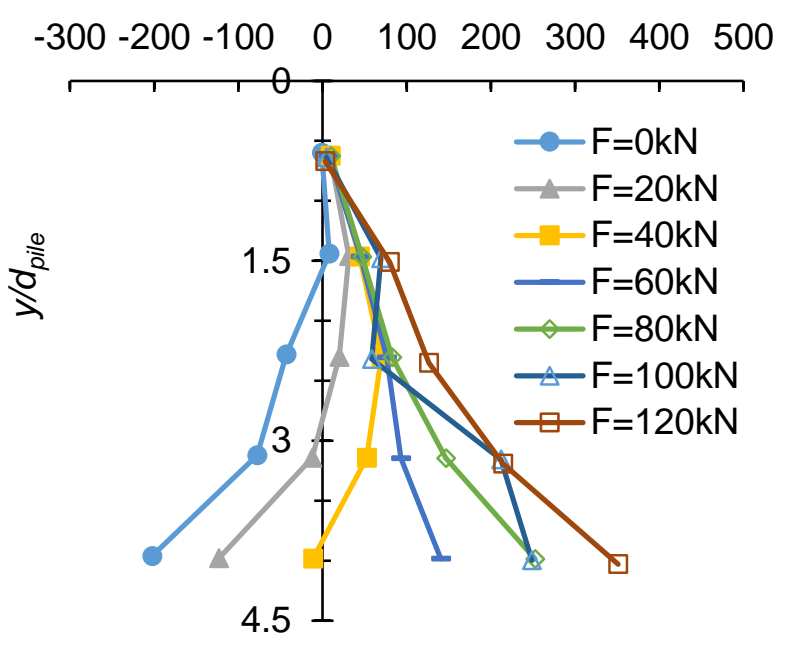

(b)

Figure 16. Mobilisation of unit shaft resistance of pile, (a) BE2, (b) DE2, during pile load tests.

\section{CONCLUSIONS}

In this paper, a discrete numerical modelling of pile installation tests was proposed. The tests were conducted with two different processes: bored pile and driven pile. Both conditions were performed with similar magnitude of pile embedded depth. The underlying mechanisms and associated micromechanics of driven and bored pile setup in dry sand are examined in numerical model pile tests.

Shaft resistance, base capacity and lateral stress were tested. Bored piles were observed to develop large 
settlements immediately during the test, while driven piles initially withstood settlements owing to an increase in available base capacity at the start of the penetration.

The main conclusions that can be drawn from this investigation are outlined below.

(1) During the installation of driven pile, pile pushes the surrounding soil to the side, thereby imposing additional loading on the soil inside the influence zone.

(2) The surrounding region of driven pile generates high lateral stress and bearing capacity.

(3) The ultimate unit shaft resistance of the driven pile is significantly larger than that of the bored pile. Friction fatigue is identified to be another major cause for the differences in shaft resistance besides the residual forces.

(4) When the measured evolution of the effective lateral stress below the pile base (level 4), as well as the porosity change near the pile shaft are compared, large differences are observed for both the bored pile and driven pile approach.

The direction of this research will be dedicated to the analysis of the mechanisms involved in the penetration process. The analysis should also focus on the interpretation of the force displacement response measured for the mechanical properties extracted from its procedure. Finally, parametric study on the numerical model should be conducted to evaluate their influence on macro-mechanical properties.

\section{Acknowledgments}

The authors would like to thank the funding supports from Zhejiang Provincial Natural Science Foundation (No. LQ18E090009); Open Fund Project of MOE Key Laboratory of Soft Soils and Geoenvironmental Engineering, Zhejiang University (2018P07); Open Fund Project of MOE Engineering Research Center of Geotechnical Drilling and Protection, China University of Geosciences (Wuhan); Research Fund of Zhejiang Sci-Tech University (No. 17052076-Y) and the National Natural Science Foundation of China (No. 41502304).

\section{Reference}

Adejumo, T. W., \& Boiko, I. L. (2013). Effect of Installation Techniques on the Allowable Bearing Capacity of Modeled Circular Piles in Layered Soil. International Journal of Science, Engineering and Technology Research (IJSETR), 2(8).

Albuquerque, P. J. R., Massad, F., Fonseca, A. V., Carvalho, D., Santos, J., \& Esteves, E. C. (2011). Effects 
of the Construction Method on Pile Performance: Evaluation by Instrumentation. Part 1: Experimental Site at the State University of Campinas.

Altaee, A., Evgin, E., \& Fellenius, B. H. (1992). Axial load transfer for piles in sand. II. Numerical analysis. Canadian Geotechnical Journal, 29(1), 21-30. doi:10.1139/t92-003

Arroyo, M., Butlanska, J., Gens, A., Calvetti, F., \& Jamiolkowski, M. (2011). Cone penetration tests in a virtual calibration chamber. Géotechnique, 61(6), 525-531.

Been, K., Jefferies, M. G., Crooks, J. H. A., \& Rothenburg, L. (1987). The cone penetration test in sands: part II, general inference of state. Géotechnique, 37(3), 285-299.

Bertrand, D., Nicot, F., Gotteland, P., \& Lambert, S. (2008). Discrete element method (DEM) numerical modeling of double-twisted hexagonal mesh. Canadian Geotechnical Journal, 45(8), 1104-1117.

Bolton, M. D., \& Gui, M. W. (1993). The study of relative density and boundary effects for cone penetration tests in centrifuge. Retrieved from UK:

Bolton, M. D., Gui, M. W., Garnier, J., Corté, J. F., Bagge, G., Laue, J., \& Renzi, R. (1999). Centrifuge cone penetration tests in sand. Géotechnique, XLIX(4), 543-552.

Broere, W., \& Tol, A. F. v. (2006). Modelling the bearing capacity of displacement piles in sand. Proceedings of the ICE - Geotechnical Engineering, 159, 195-206. Retrieved from

Butlanska, J., Arroyo, M., \& Gens, A. (2009). Homogeneity and symmetry in DEM models of cone penetration. Paper presented at the Proc. AIP Conf. on Powders and Grains.

Butlanska, J., Arroyo, M., \& Gens, A. (2010). Virtual calibration chamber CPT tests on Ticino sand. Paper presented at the Proc. 2nd International Symposium on Cone Penetration Testing, CPT.

Calvetti, F., \& Nova, R. (2005). Micro-macro relationships from DEM simulated element and in-situ tests. Paper presented at the 5th International Conference of Micromechanics.

Cheng, Y. P., Nakata, Y., \& Bolton, M. D. (2003). Discrete element simulation of crushable soil. Géotechnique, 53(7), 633-641.

Cundall, P. A. (2001). A discontinuous future for numerical modelling in geomechanics? Proceedings of the Institution of Civil Engineers - Geotechnical Engineering, 149(1), 41-47. doi:doi:10.1680/geng.2001.149.1.41

Cundall, P. A., \& Strack, O. D. (1979). A discrete numerical model for granular assemblies. Géotechnique, 29(1), 47-65.

De Gennaro, V., Frank, R., \& Said, I. (2008). Finite element analysis of model piles axially loaded in sands. Rivista Italiana di Geotechnica(2), 44-62.

Duan, N. (2016). Mechanical Characteristics of Monopile Foundation in Sand for Offshore Wind Turbine. $(\mathrm{PhD})$, University College London.

Duan, N., \& Cheng, Y. P. (2016). A Modified Method of Generating Specimens for 2D DEM Centrifuge Model. Paper presented at the GEO-CHICAGO 2016: Sustainability, Energy, and the Geoenvironment, Chicago.

Duan, N., Cheng, Y. P., \& Xu, X. M. (2017). Distinct-element analysis of an offshore wind turbine monopile under cyclic lateral load. Proceedings of the Institution of Civil Engineers-Geotechnical Engineering, 170(GE6), 517-533.

Feng, Y. T., Han, K., Owen, D. R. J., \& Loughran, J. (2009). On upscaling of discrete element models: similarity principles. Engineering Computations, 26(6), 599-609.

Feng, Y. T., \& Owen, D. R. J. (2014). Discrete element modelling of large scale particle systems-I: exact scaling laws. Computational Particle Mechanics, 1(2), 159-168.

Huang, A. B., \& Ma, M. Y. (1994). An analytical study of cone penetration tests in granular material. Canadian Geotechnical Journal, 31(1), 91-103.

Itasca. (2004). PFC User Manual, version 3.1. USA: Itasca Consulting Group Inc.

Jamiolkowski, M., Lo Presti, D., \& Manassero, M. (2003). Evaluation of Relative Density and Shear Strength of Sands from CPT and DMT Soil Behavior and Soft Ground Construction (pp. 201-238): American Society of Civil Engineers.

Jiang, M., Dai, Y., Cui, L., Shen, Z., \& Wang, X. (2014). Investigating mechanism of inclined CPT in 
granular ground using DEM. Granular Matter, 16(5), 785-796.

Jiang, M. J., Yu, H. S., \& Harris, D. (2010). Discrete element modelling of deep penetration in granular soils. International Journal for Numerical \& Analytical Methods in Geomechanics, 30(4), 335-361.

Leung, C. F., Lee, F. H., \& Yet, N. S. (2001). Centrifuge model study on pile subject to lapses during installation in sand. International Journal of Physical Modelling in Geotechnics, 1(1), 47-57. doi:doi:10.1680/ijpmg.2001.010105

Lin, J., \& Wu, W. (2012). Numerical study of miniature penetrometer in granular material by discrete element method. Philosophical Magazine, 92(28-30), 3474-3482. doi:10.1080/14786435.2012.706373

Liu, J.-w., Yu, F., Zhang, Z.-m., \& Wang, N. (2013). Simulation of post-installation residual stress in preformed piles based on energy conservation. Rock and Soil Mechanics, 4, 041.

Liu, J.-w., Zhang, Z.-m., Yu, F., \& Xie, Z.-z. (2012). Case history of installing instrumented jacked open-ended piles. Journal of Geotechnical and Geoenvironmental Engineering, 138(7), 810-820.

Marshall, A. M., Elkayam, I., Klar, A., \& Mair, R. J. (2010). Centrifuge and discrete element modelling of tunnelling effects on pipelines. Paper presented at the International Conference on Physical Modelling in Geotechnics.

Maynar, M., \& Rodríguez, L. (2005). Discrete Numerical Model for Analysis of Earth Pressure Balance Tunnel Excavation. Journal of Geotechnical and Geoenvironmental Engineering, 131(10), 1234-1242. doi:10.1061/(ASCE)1090-0241(2005)131:10(1234)

Mcdowell, G., Falagush, O., \& Yu, H.-S. (2012). A particle refinement method for simulating DEM of cone penetration testing in granular materials. Géotechnique Letters, 2(July-September), 141-147.

O’Sullivan, C. (2011). Particle-Based Discrete Element Modeling: Geomechanics Perspective. International Journal of Geomechanics, 11(6), 449-464.

Poulos, H. G. (1987). Analysis of residual stress effects in piles. Journal of Geotechnical Engineering, 113(3), 216-229.

Robertson, P. K. (1986). In situ testing and its application to foundation engineering. Canadian Geotechnical Journal, 23(4), 573-594.

Schertmann, J. (1977). Guidelines for cone penetration test: performance and design. Washington: Dept. of Transportation, Federal Highway Administration, Offices of Research and Development, Implementation Division.

Schofield, A. N. (1980). Cambridge Geotechnical Centrifuge Operations. Géotechnique, 30, 227-268. Retrieved from

Sladen, J. A. (1989). Problems with interpretation of sand state from cone penetration test. Géotechnique, 39(2), 323-332.

Ting, J., Corkum, B., Kauffman, C., \& Greco, C. (1989). Discrete Numerical Model for Soil Mechanics. Journal of Geotechnical Engineering, 115(3), 379-398.

Vallejo, L., \& Lobo-Guerrero, S. (2005). DEM analysis of crushing around driven piles in granular materials. Géotechnique(55), 617-623.

Wang, J., \& Zhao, B. (2014). Discrete-continuum analysis of monotonic pile penetration in crushable sands. Canadian Geotechnical Journal, 51(10), 1095-1110. doi:10.1139/cgj-2013-0263

Wang, Y. H., \& Leung, S. C. (2008). A particulate-scale investigation of cemented sand behavior. Canadian Geotechnical Journal, 45(1), 29-44. doi:10.1139/T07-070

Wehnert, M., \& Vermeer, P. (2004). Numerical analyses of load tests on bored piles. Numerical methods in geomechanics-NUMOG IX, 505-511.

Yang, Z., Jardine, R., Zhu, B., \& Rimoy, S. (2013). Stresses Developed around Displacement Piles Penetration in Sand. Journal of Geotechnical and Geoenvironmental Engineering, 140(3), 04013027.

Yu, F. (2004). Behavior of large capacity jacked piles. (Ph.D), University of Hong Kong.

Yu, H. S. (2006). The First James K. Mitchell Lecture In situ soil testing: from mechanics to interpretation. Geomechanics and Geoengineering, 1(3), 165-195. 
Zhang, L. M., \& Wang, H. (2007). Development of Residual Forces in Long Driven Piles in Weathered Soils. Journal of Geotechnical and Geoenvironmental Engineering, 133(10), 1216-1228. doi:10.1061/(ASCE)1090-0241(2007)133:10(1216)

Zhang, L. M., \& Wang, H. (2009). Field study of construction effects in jacked and driven steel H-piles. Géotechnique, 59(1), 63-69. doi:doi:10.1680/geot.2008.T.029

Zhang, Z., \& Wang, Y.-H. (2015). Three-dimensional DEM simulations of monotonic jacking in sand. Granular Matter, 17(3), 359-376. 